\title{
Liquefaction of Lignosulfonate in Supercritical Ethanol Using Alumina-Supported NiMo Catalyst
}

Ghafarnejad Parto, Soheila; Christensen, Jakob Munkholt; Pedersen, Lars Saaby; Hansen, Asger Baltzer; Tjosås, Freddy; Spiga, Cristiano; Damsgaard, Christian Danvad; Larsen, Daniel Bo; Duus, Jens Øllgaard; Jensen, Anker Degn

Published in:

Energy and Fuels

Link to article, DOI:

10.1021/acs.energyfuels.8b03519

Publication date:

2019

Document Version

Publisher's PDF, also known as Version of record

Link back to DTU Orbit

Citation (APA):

Ghafarnejad Parto, S., Christensen, J. M., Pedersen, L. S., Hansen, A. B., Tjosås, F., Spiga, C., Damsgaard, C. D., Larsen, D. B., Duus, J. Ø., \& Jensen, A. D. (2019). Liquefaction of Lignosulfonate in Supercritical Ethanol Using Alumina-Supported NiMo Catalyst. Energy and Fuels, 33(2), 1196-1209.

https://doi.org/10.1021/acs.energyfuels.8b03519

\section{General rights}

Copyright and moral rights for the publications made accessible in the public portal are retained by the authors and/or other copyright owners and it is a condition of accessing publications that users recognise and abide by the legal requirements associated with these rights.

- Users may download and print one copy of any publication from the public portal for the purpose of private study or research.

- You may not further distribute the material or use it for any profit-making activity or commercial gain

- You may freely distribute the URL identifying the publication in the public portal 


\title{
Liquefaction of Lignosulfonate in Supercritical Ethanol Using Alumina-Supported NiMo Catalyst
}

\author{
Soheila Ghafarnejad Parto, ${ }^{\dagger}$ Jakob Munkholt Christensen, ${ }^{\dagger}$ Lars Saaby Pedersen, ${ }^{\ddagger}$ Asger Baltzer Hansen, \\ Freddy Tjosås, ${ }^{\S}$ Cristiano Spiga, ${ }^{\|}$Christian Danvad Damsgaard, ${ }^{\|}$Daniel Bo Larsen, ${ }^{\perp} \mathbb{C}$ \\ Jens Øllgaard Duus, ${ }^{\perp}{ }^{\circ}$ and Anker Degn Jensen ${ }^{*}, \dagger$ \\ ${ }^{\dagger}$ Chemical and Biochemical Engineering, Technical University of Denmark, 2800 Kgs. Lyngby, Denmark \\ ${ }^{\ddagger}$ Haldor Topsøe A/S, Haldor Topsøes Allé 1, 2800 Kgs. Lyngby, Denmark \\ ${ }^{\S}$ Borregaard A/S, Hjalmar Wesselsvei 2, NO-1721 Sarpsborg, Norway \\ "Center for Electron Nanoscopy, Technical University of Denmark, 2800 Kgs. Lyngby, Denmark \\ ${ }^{\perp}$ Department of Chemistry, Technical University of Denmark, 2800 Kgs. Lyngby, Denmark
}

\section{Supporting Information}

\begin{abstract}
Lignosulfonate was subjected to a reductive catalytic degradation in ethanol medium at $310{ }^{\circ} \mathrm{C}$ in the presence of alumina supported NiMo catalysts and $\mathrm{H}_{2}$. The liquid and solid products were analyzed with size exclusion chromatography (SEC), gas chromatography mass spectrometry (GC-MS), two-dimensional gas chromatography $(\mathrm{GC} \times \mathrm{GC})$, heteronuclear single quantum coherence nuclear magnetic resonance (HSQC NMR) and elemental analysis. The highest oil yield and the lowest char yield obtained was 88 and $15 \mathrm{wt} \%$, respectively. The liquefied species were mainly dimers and oligomers with minor yields of monomers. The catalyst was important for stabilization of reactive intermediates either by hydrogenation or coupling with ethanol. Simultaneous deoxygenation and desulfurization reactions took place in the presence of the catalyst; the oxygen and sulfur content in the oil fraction obtained after $4 \mathrm{~h}$ reaction time were 11.2 and 0.1 wt \%, indicating considerable deoxygenation and desulfurization compared to the lignosulfonate feedstock $(\mathrm{O}, 30.8 \mathrm{wt} \% ; \mathrm{S}, 3.1$ wt \%). The effect of the reaction parameters such as temperature, reaction time and catalyst mass was studied. It was observed that by increasing the temperature from 260 to $310{ }^{\circ} \mathrm{C}$ the degradation increased, however, the SEC analysis showed that the degradation progressed only to a certain size range dimers to oligomers in the reaction temperatures studied. Investigating the effect of reaction time of $1,2,3$, and $4 \mathrm{~h}$ indicated that degradation, deoxygenation, desulfurization and alkylation reactions progressed over time. The reusability of the catalyst without any pretreatment was confirmed by an almost constant oil yield in three repeated experiments with the same catalyst batch. The results show that alumina supported NiMo catalysts are very promising catalysts for conversion of lignosulfonate to liquid products.
\end{abstract}

\section{INTRODUCTION}

The depletion of fossil fuels, along with the increase of the global population and therefore the increase of the energy demand, has stimulated the interest in development of nonfossil-based and renewable sources of energy and chemicals. Moreover, increasing awareness of $\mathrm{CO}_{2}$ emission and associated environmental issues, such as global warming, encourages the utilization of carbon neutral and sustainable energy resources. ${ }^{1}$ Among different renewable energies, biomass is the only source of organic carbon that can be employed for production of chemicals. ${ }^{2}$ Lignocellulosic biomass is comprised of cellulose, hemicellulose and lignin. The cellulose and hemicellulose are mainly used in the pulp and paper industry, where lignin is left as byproduct, and is mainly combusted to supply the energy for the process. The recent development of second-generation bioethanol plants also produces considerable amounts of lignin as byproduct. Lignin is mainly composed of three building blocks; coumaryl alcohol, coniferyl alcohol, and synapyl alcohol connected via $\mathrm{C}-\mathrm{C}$ and $\mathrm{C}-\mathrm{O}$ bonds ${ }^{3}$ and could be a source of aromatic chemicals, if the interbuilding block bonds are selectively cleaved. The most available types of technical lignins are kraft lignin, sulfite lignin (lignosulfonate), soda lignin (alkali lignin), enzymatically extracted lignin, and organosolv lignin. Despite the high potential of lignin as a source of chemicals, only $1-2 \%$ is commercially used, which are mostly related to the applications of lignosulfonate. ${ }^{4}$ Vanillin $^{5}$ and additives for batteries are some of the high value products produced from lignosulfonate. However, the development of liquid fuels and perhaps even other high-value chemicals from this feedstock is of interest. Reductive solvolysis of lignin is a promising step in the production of low oxygen content fuel and chemicals via hydrogenolysis and hydrodeoxygenation (HDO). A solvent can solubilize lignin, contribute to the cleavage of the $\mathrm{C}-\mathrm{O}$ bonds and stabilize the reactive intermediates. ${ }^{6,7}$ The reductive conversion may be accompanied by presence of a heterogeneous catalyst. Transition metals and hydrotreating catalysts are among those investigated. ${ }^{8-11}$

One of the advantages of biomass as an energy source is its low sulfur content. ${ }^{12}$ However, sulfur can be introduced into

Received: October 8, 2018

Revised: December 13, 2018

Published: January 15, 2019 


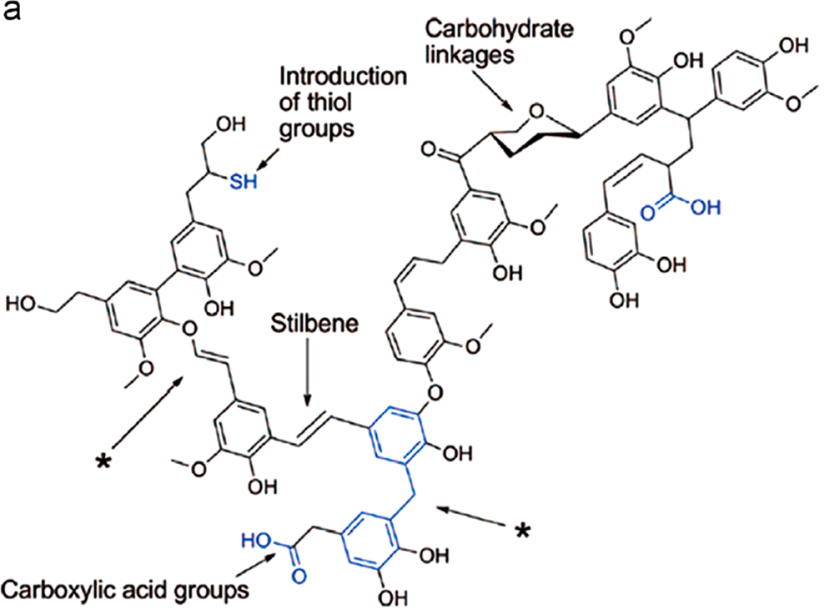

b

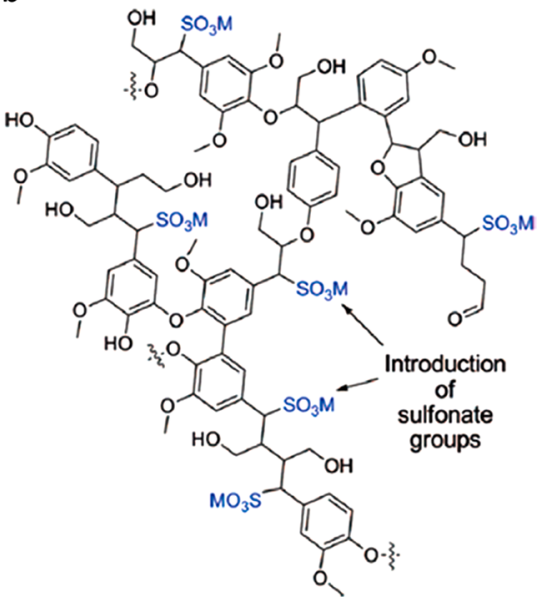

Figure 1. Proposed structures for (a) kraft lignin and (b) sulfite lignin, reprinted (adopted) with permission from Zakzeski et al., ${ }^{15}$ Copyright 2010 American Chemical Society, and Mahmmod et al., ${ }^{16}$ Copyright 2016 Elsevier.

the structure of lignin in conventional pulping processes: kraft lignin and sulfite lignin, as the major types of technical lignin, contain thiol and sulfonate groups, respectively (see Figure 1). The poisoning effects of sulfur on noble and non-noble transition metal catalysts are known. ${ }^{13,14}$ Therefore, employing a sulfur resistant catalyst for catalytic degradation of kraft lignin and lignosulfonate is essential.

The sulfur resistant nickel- $(\mathrm{Ni})$ or cobalt- (Co) promoted molybdenum- (Mo) and tungsten- (W) based catalysts are industrially used for hydrotreating purposes including HDO, hydrodesulfurization (HDS) and hydrodenitrogenation (HDN). ${ }^{17}$ The promotion with $\mathrm{Ni}$ or Co increases the activity of the edge sites in $\mathrm{MoS}_{2}$ slabs. ${ }^{18,19}$ Nickel-promoted Mo (NiMo) and cobalt-promoted Mo ( $\mathrm{CoMo}$ ) catalysts are initially in oxide form and therefore should be activated prior to use by sulfidation and formation of the active NiMoS and CoMoS phases. Such bimetallic catalysts have gained interest in solvothermal conversion of biomass and lignin. A recent patent reports ${ }^{20}$ reductive conversion of biomass in solvents such as ethanol and ethylene glycol over supported catalysts comprised of $\mathrm{S}, \mathrm{Mo} / \mathrm{W}$, and $\mathrm{Co}, \mathrm{Ni}$ or a mixture of them at $180-300{ }^{\circ} \mathrm{C}$. Narani and co-workers ${ }^{21}$ studied conversion of kraft lignin in the presence of NiW/AC, NiMo/AC, and $\mathrm{CoMo} / \mathrm{AC}$ catalysts in methanol as solvent at $320{ }^{\circ} \mathrm{C}$. They observed 28 wt \% monomer yields over the sulfided NiW/AC catalyst, with alkyl phenols and guaiacols being the main products. $^{21}$ Cattelan et al. ${ }^{22}$ observed higher yields of aromatics from conversion of kraft lignin in the presence of an $\mathrm{MoS}_{2}$-based catalyst compared to noncatalytic conversion in supercritical ethanol and nitrogen atmosphere at $280{ }^{\circ} \mathrm{C}$ : While almost similar conversions were obtained in the absence and presence of catalyst (85-86 wt \%), the yield of aromatic compounds increased from $10.2 \mathrm{wt} \%$ to $17.8 \mathrm{wt} \%$ in catalytic conditions. ${ }^{22}$ Joffres et al. ${ }^{23,24}$ observed cleavage of $\beta$-O-4 and $\alpha$-O-4 bonds in reductive degradation of wheat straw soda lignin over $\mathrm{NiMoS} / \mathrm{Al}_{2} \mathrm{O}_{3}$ at $350{ }^{\circ} \mathrm{C}$ in tetralin solvent. According to them ${ }^{23}$ demethoxylation reactions via cleavage of aryl alkyl ether bonds, hydrogenation of aliphatic double bonds and dehydroxylation of aliphatic $\mathrm{OH}$ groups took place during transformation of the lignin.

Despite the fact that lignosulfonate is a major commercial type of technical lignin, only a few studies have targeted conversion of lignosulfonate. ${ }^{25,26}$ Horacek et al. ${ }^{27}$ investigated conversion of sodium lignosulfonate (Na-LS) over alumina supported reduced $\mathrm{Ni}$ and NiMo catalyst in 5 wt \% aqueous solution at $320{ }^{\circ} \mathrm{C}$ in a tubular reactor with hydrogen flow of 5 $\mathrm{N} \mathrm{mL} / \mathrm{min}$. They observed formation of alkyl substituted guaiacols and phenols in the products, with a guaiacol yield of 1.8 and 1.5 wt $\%$ over $\mathrm{Ni} / \mathrm{Al}_{2} \mathrm{O}_{3}$ and $\mathrm{NiMo} / \mathrm{Al}_{2} \mathrm{O}_{3}$, respectively. ${ }^{27} \mathrm{~A}$ drawback of using water as reaction medium is its poor performance in inhibiting condensation reactions between radical fragments. ${ }^{28}$ It was previously shown by Huang et al. $^{7}$ that ethanol can inhibit repolymerization reactions by $\mathrm{O}$ - and $\mathrm{C}$ - alkylation reactions. ${ }^{7}$

In this work, we investigated the conversion of lignosulfonate in ethanol medium in the presence of a NiMo catalyst supported on $\mathrm{Al}_{2} \mathrm{O}_{3}$ in the presence of 26 bar $\mathrm{H}_{2}$. The composition and properties of the liquid, solid and gaseous compounds was comprehensively evaluated and the role of solvent was elaborated on. Analytical techniques such as GCMS, GC $\times$ GC, GC equipped with thermal conductivity detector (GC-TCD), SEC, HSQC NMR, elemental analysis and ion-coupled plasma-optical emission spectroscopy (ICPOES) were used for analysis of the products. The presence of the catalyst increased the yield of liquefied fraction and promoted ethanol end-capping reactions. Moreover, the necessity of presulfidation of the NiMo catalyst for conversion of the lignosulfonate, which contains 3.1 wt \% sulfur, was investigated. Additionally, we studied the effect of reaction parameters such as reaction temperature, reaction time and catalyst loading to maximize the yield of the liquefied fraction.

\section{EXPERIMENTAL SECTION}

2.1. Materials. Spruce based Na-LS was provided by Borregaard A/S. According to Mortensen et al., ${ }^{29}$ potassium is detrimental to the $\mathrm{HDO}$ activity of supported $\mathrm{NiMoS}$, and sodium is expected to have a similar effect. The original Na-LS contained $7.3 \mathrm{wt} \% \mathrm{Na}$ and $0.01 \mathrm{wt}$ $\% \mathrm{~K}$, and therefore, the $\mathrm{Na}^{+}$and $\mathrm{K}^{+}$were exchanged with $\mathrm{H}^{+}$ions, by ion-exchange using Amberlite $120 \mathrm{H}$ resin as described elsewhere, ${ }^{30}$ in order to avoid potential interactions with the catalyst. The sulfonic acid form of lignosulfonate is denoted H-LS. After the ion-exchange, the amount of $\mathrm{Na}^{+}$and $\mathrm{K}^{+}$decreased to 0.1 and $0.001 \mathrm{wt} \%$ on a dry matter basis, respectively. The solvent used in the conversion of lignin was ethanol (VWR, 99.9\%). Other chemicals including the gases for GC analysis were of analytical grade and used without any pretreatment. 
2.2. Catalyst. Two catalyst samples were used in the experiments. The catalyst used in most of the tests was a commercial NiMo/ $\mathrm{Al}_{2} \mathrm{O}_{3}$ provided by Haldor Topsøe A/S (named NiMo-I). For studies on the sulfidation state of the catalyst by transmission electron microscopy energy-dispersive X-ray spectroscopy (TEM-EDX) analysis, a batch of $10 \mathrm{~g}$ alumina supported NiMo sample was prepared in-house (named NiMo-II). The support of this catalyst was $\gamma-\mathrm{Al}_{2} \mathrm{O}_{3}$ from Saint-Gobain with a surface area of $254.7 \mathrm{~m}^{2} / \mathrm{g}$ and pore volume of $1.11 \mathrm{~mL} / \mathrm{g}$. The support material was crushed to $150-300 \mu \mathrm{m}$. The catalyst was prepared by successive incipient wetness impregnation stages: First the support was impregnated with $15 \mathrm{wt} \%$ nominal concentration of Mo using an aqueous solution of ammonium heptamolybdate tetrahydrate $\left(\mathrm{NH}_{4}\right)_{6} \mathrm{Mo}_{7} \mathrm{O}_{24} \cdot 4 \mathrm{H}_{2} \mathrm{O}$ (Sigma-Aldrich, purity $\geq 99 \%$ ) as precursor. The precursor solution was subsequently added dropwise to the support. The water was later evaporated in an oven at $50{ }^{\circ} \mathrm{C}$, overnight. A $3 \mathrm{wt} \%$ nominal concentration of $\mathrm{Ni}$ was then added in a second impregnation step, using an aqueous solution of nickel nitrate hexahydrate $\mathrm{Ni}\left(\mathrm{NO}_{3}\right) \cdot 6 \mathrm{H}_{2} \mathrm{O}$ (Sigma-Aldrich purity $\geq 99.999 \%$ ), followed by evaporation of water. The in-house synthesized catalyst was calcined by heating to $500{ }^{\circ} \mathrm{C}$ at a rate of $5{ }^{\circ} \mathrm{C} / \mathrm{min}$ in $2.5 \mathrm{~L} / \mathrm{min}$ flow of $20 \mathrm{vol} \% \mathrm{O}_{2}$ and $80 \mathrm{vol} \% \mathrm{~N}_{2}$ and holding at this temperature for $3 \mathrm{~h}^{31}$ The $\mathrm{Mo}$ and $\mathrm{Ni}$ content of the calcined catalyst was measured by ICP analysis being 12.8 and $2.3 \mathrm{wt} \%$, respectively, which corresponds to a $\mathrm{Ni} / \mathrm{Mo}$ molar ratio of 0.3 . This molar ratio is recognized as the optimal value for HDS activity. ${ }^{32}$ The catalyst was used in oxide form in most of the experiments, however, in a few experiments the catalyst was presulfided. Presulfidation of NiMo catalyst was achieved using $1-5 \mathrm{~mL}$ dimethyl disulfide (DMDS) in reductive atmosphere $\left(30 \mathrm{bar} \mathrm{H}_{2}\right.$, loaded at $\left.\mathrm{RT}\right)$ at $400{ }^{\circ} \mathrm{C}$, overnight. The sulfur content of the presulfided home-synthesized NiMo-II catalyst was $10.0 \mathrm{wt} \%$ as determined by ICP analysis, which corresponds to the formation of $\mathrm{MoS}_{2}, \mathrm{NiS}$, and $\mathrm{Ni}_{2} \mathrm{~S}_{3}$.

2.3. Lignosulfonate Depolymerization Reactions. The experiments were conducted in a 4566 series Parr reactor (volume of $0.3 \mathrm{~L}$ ) with the loadings in most of the experiments being $1 \mathrm{~g}$ of catalyst, $10 \mathrm{~g}$ of $\mathrm{H}-\mathrm{LS}$, and $100 \mathrm{~mL}$ of ethanol as solvent. In a few experiments, $0.5 \mathrm{~g}$ of catalyst, $5 \mathrm{~g}$ of H-LS, and $50 \mathrm{~mL}$ of solvent were loaded. The reactor was flushed with $\mathrm{N}_{2}$ for three times and subsequently charged with 26 bar $\mathrm{H}_{2}$ at room temperature (RT). Then the reactor was heated to the desired temperature (typically $310{ }^{\circ} \mathrm{C}$ ) while stirring with an approximate heating rate of $8.5{ }^{\circ} \mathrm{C} / \mathrm{min}$. Stirring was important to avoid that lignin deposited at the reactor bottom and was exposed to high temperature causing severe charring. The initiation of reaction time was considered from the moment that the temperature inside the reactor reached the set point. At the end of the reaction time (typically $3 \mathrm{~h}$ ), the reactor was quickly cooled by quenching the reactor vessel in an ice bath. Once the temperature inside the reactor reached ambient condition, gas samples were collected using Tedlar gas bags. Before opening the reactor, the gas phase was discharged to the vent and the reactor was flushed with $\mathrm{N}_{2}$ gas. The effect of adding a sulfur source was studied in an experiment by adding $1 \mathrm{~mL}$ of DMDS to the reaction medium before reaction. A few experiments were also conducted in the absence of catalyst for comparison.

At the end of each experiment, the solid and the liquid products of the reactions were separated by vacuum filtration over a preweighed filter paper. The filter cake was washed with $100 \mathrm{~mL}$ ethanol to ensure removal of the light products. The filtrate and ethanol used for rinsing the cake were collected and the solid phase was dried overnight at 60 ${ }^{\circ} \mathrm{C}$. The solid phase was comprised of spent catalyst, ash, char and possibly unreacted/repolymerized lignin. The heavy and light fractions in the liquid phase were separated using a rotary evaporator at $35{ }^{\circ} \mathrm{C}, 5 \mathrm{mbar}$ vacuum and a rotation speed of $130 \mathrm{rpm}$. Ethanol and the light products were evaporated (light phase), and a thick liquid phase remained unevaporated, regarded as "oil" (heavy liquid phase). During the workup procedure, the masses of the different fractions were carefully measured. A mass loss of 6-15 wt \% was observed during the workup procedure, mainly in the filtration step and was likely mainly due to loss of solvent.
The yields of the oil and solid fractions were calculated based on the dry and ash free (DAF) H-LS (eq 1 and 2, respectively). The mass of the solid organics (originating from lignin) was calculated by subtracting the mass of ash and loaded catalyst from the total solid mass obtained from filtration.

$$
\begin{aligned}
& \text { oil yield }=\frac{m_{\text {Oil }}}{m_{D A F H-L S}} \times 100 \\
& \text { solid yield }=\frac{m_{\text {solid residue }}-m_{\text {ash }}-m_{\text {catalyst }}}{m_{D A F H-L S}} \times 100
\end{aligned}
$$

2.4. Characterizations and Analytical Techniques. The molecular weight distribution of lignin, solid and oil fractions was evaluated by SEC using an Agilent 1100 series HPLC equipped with a UV-vis detector. The precolumn $(50 \times 8 \mathrm{~mm}, 5 \mu \mathrm{m})$ and column $(300 \times 8 \mathrm{~mm}, 5 \mu \mathrm{m})$ were purchased from polymer Standard Service Company Polarsil. A 90/10 wt \% dimethyl sulfoxide (DMSO)/water solution containing $0.05 \mathrm{M} \mathrm{LiBr}$ was used as solvent. The samples were dissolved in the solvent with a concentration of approximately 2 $\mathrm{mg} / \mathrm{mL}$ and $10 \mu \mathrm{L}$ of sample was injected for each analysis. The column oven temperature was set to $80{ }^{\circ} \mathrm{C}$ to facilitate the elution of solvent and the elution flow rate was set to $1 \mathrm{~mL} / \mathrm{min}$. Phenol (Mw: $94 \mathrm{~g} / \mathrm{mol}$ ), guaiacylglycerol $\beta$-guaiacyl ether (GGGE) ( $\mathrm{Mw}: 320 \mathrm{~g} /$ $\mathrm{mol}$ ), and tannic acid (Mw: $1701 \mathrm{~g} / \mathrm{mol}$ ) were used as representative standards for lignin monomers, dimers and polymers. The wavelength detected by the UV-vis detector was $280 \mathrm{~nm}$, which is the wavelength suitable for detection of aromatic species. The compounds with higher molecular weight are expected to be detected at lower retention times compared to the compounds with lower molecular weight.

The oil and light fractions were analyzed using a Shimadzu QP 2010 Ultra GC-MS-FID apparatus equipped with a Supelco Equity 5 column. Identification and quantification of the samples were performed by the MS and flame ionization detector (FID), respectively. For each analysis, a weighed amount of oil sample was diluted in $10 \mathrm{~mL}$ ethanol. The initial temperature for the GC column was set to $40{ }^{\circ} \mathrm{C}$ and the column was heated to $250{ }^{\circ} \mathrm{C}$ with a heating rate of $10^{\circ} \mathrm{C} / \mathrm{min}$ and kept at this temperature for $5 \mathrm{~min}$. A split ratio of 90 was used in the injection section. The MS was intentionally turned off between 2.4 to $4.0 \mathrm{~min}$ in order to avoid saturation by the high concentration of ethanol. Product identification was performed using the NIST 8 library. The selectivity of the compounds that were sufficiently volatile to pass through the GC column was calculated by the ratio of the FID-area of each compound relative to the total FIDarea.

HSQC NMR experiments were performed on a $400 \mathrm{MHz}$ Bruker Ascend magnet with an Avance II console and equipped with a Prodigy cryoprobe, at $400.13 \mathrm{MHz}$ for ${ }^{1} \mathrm{H}$ and 100.61 for ${ }^{13} \mathrm{C}$ using the standard Bruker pulse sequence. The samples were prepared by dissolving them in DMSO- $d_{6}$. The experiments were recorded with a sweep width of $12 \mathrm{ppm}$ in ${ }^{1} \mathrm{H}$ and 2048 points and 256 increments in the indirect dimension $\left({ }^{13} \mathrm{C}\right)$ covering $165 \mathrm{ppm}$. The delay for magnetization transfer delay was calculated to be optimal for a onebond coupling for $145 \mathrm{~Hz}$. Data were processed and plotted using Mnova software.

An Agilent 7890A series GC-TCD detector was used for identification and quantification of gaseous products. The gas injection into the GC was achieved using a fixed pressure pump. $\mathrm{H}_{2}$ was analyzed with an arrangement of a $6 \mathrm{ft}$ Haysep $\mathrm{Q}$ and $5 \AA$ molecular sieve columns, where $\mathrm{Ar}$ was the carrier gas. The gases $\mathrm{N}_{2}$, $\mathrm{O}_{2}, \mathrm{CO}, \mathrm{CO}_{2}, \mathrm{CH}_{4}, \mathrm{C}_{2} \mathrm{H}_{4}$, and $\mathrm{C}_{2} \mathrm{H}_{6}$, were detected in a line where He was the carrier gas with a column arrangement of $3 \mathrm{ft}$ Haysep $\mathrm{Q}$ HP-Plot and $5 \AA$. The calibration curves were created using certified gas mixtures from AGA. The moles of each gas were calculated by the gas phase analysis from the GC and the cold pressure of the autoclave at the end of each experiment assuming ideal gas behavior.

The oil phases from both noncatalytic and catalytic reactions were analyzed with GC $\times$ GC analysis on a LECO Pegasus GC $\times$ GCTOFMS equipped with two columns: The first column was a $25 \mathrm{~m} \times$ $0.25 \mathrm{~mm}$ i.d. and $0.25 \mu \mathrm{m}$ film of ZB-1701 connected to a second 
column which was a $1.5 \mathrm{~m} \times 0.18 \mathrm{~mm}$ i.d. and $0.18 \mu \mathrm{m}$ film of Rtx-5. The oven temperature of the first column was set to $40{ }^{\circ} \mathrm{C}$ for $2 \mathrm{~min}$, then heated to $300{ }^{\circ} \mathrm{C}$ with a heating rate of $5{ }^{\circ} \mathrm{C} / \mathrm{min}$ and was kept at $300{ }^{\circ} \mathrm{C}$ for $5 \mathrm{~min}$. The second oven had an offset of $5{ }^{\circ} \mathrm{C}$ from first column. Pulsed split with split ratio of 25 and pressure of 20 psi for 2 min was applied. The carrier gas was He with constant flow of 1.5 $\mathrm{mL} / \mathrm{min}$. The modulation time was $8 \mathrm{~s}$ throughout the run. The MS acquisition was acquired with mass range of $41-441 \mathrm{~m} / z$ at 100 . The ion source temperature was set to $225{ }^{\circ} \mathrm{C}$. The MS plots were analyzed using LECO ChromaTOF software, version 4.50.

The content of organic carbon, hydrogen, sulfur and nitrogen in $\mathrm{H}-$ LS, oil and solid fractions were analyzed using a EuroVector EA 3000 CHNS analyzer. The measurement was done by combustion of a 1 mg encapsulated sample at $980{ }^{\circ} \mathrm{C}$ and further quantification of evolved $\mathrm{CO}_{2}, \mathrm{H}_{2} \mathrm{O}, \mathrm{N}_{2}$ and $\mathrm{SO}_{2}$ by GC-TCD. The oxygen percentage was calculated by subtraction of the $\mathrm{C}, \mathrm{H}, \mathrm{N}, \mathrm{S}$ and ash percentages of each sample. The ash content of H-LS and also solid residues was determined by combusting an aliquot of approximately $1 \mathrm{~g}$ in an oven at $600{ }^{\circ} \mathrm{C}$. The solid residues from the catalytic experiments were mixed with spent catalyst. It was assumed that the catalyst is not combustible and is left with the ash after the combustion. Oxidation of sulfides to oxides may be expected by combustion, however, the minor differences caused by this was not taken into account.

ICP-OES was used for quantification of the $\mathrm{Ni}, \mathrm{Mo}$ and $\mathrm{S}$ content in NiMo-II catalyst samples. The samples were melted together with potassium pyrosulfate, dissolved in a solution of water and $\mathrm{HCl}$ and analyzed with optical emission spectroscopy. Moreover, the sulfur content in the oil fractions was measured by ICP-OES. The samples were prepared by dilution of a weighed amount of oil samples in ethanol.

The presulfided NiMo-II catalyst before reaction, spent presulfided NiMo-II after reaction, and also spent non-presulfided NiMo-II after reaction were analyzed with TEM-EDX analysis. The samples were dispersed on a grid and mounted on an FEI single tilt holder. The TEM images were obtained using a FEI Tecnai T20 G2 S-TEM microscope operating at $200 \mathrm{keV}$. The EDX spectra were acquired with an Oxford X-max silicon-drift detector (SDD) with an active area of $80 \mathrm{~mm}^{2}$.

\section{RESULTS AND DISCUSSION}

3.1. Depolymerization of Lignosulfonate. The results from conversion of H-LS are summarized in Table 1. The reproducibility was confirmed by repeating selected experiments. A high yield of $67 \pm 2$ wt $\%$ oil phase was obtained from conversion of H-LS over the NiMo-I catalyst at $310{ }^{\circ} \mathrm{C}$ (Table 1, entry 1 ) and the yield of solid fraction was $38 \pm 2 \mathrm{wt}$ $\%$. The catalyst was used in its oxide form, and it was assumed that it may become sulfided in situ by reaction with sulfur from lignosulfonate. This will be discussed later based on the results from the NiMo-II catalyst. Noticeably, the sum of the solid and oil yields exceeded $100 \%$, most likely due to the solvent incorporation. This has been observed before by $\mathrm{Ma}$ et al., ${ }^{33}$ where 164 wt \% oil yield was reported from ethanolysis of kraft lignin over $\alpha-\mathrm{MoC}_{1-x} / \mathrm{AC}$ at $280{ }^{\circ} \mathrm{C}$, indicating considerable ethanol conversion and incorporation to the liquid products. The observed oil yield in this work at $310{ }^{\circ} \mathrm{C}$ and $3 \mathrm{~h}$ reaction time is among the highest yields reported from one-pot mild solvothermal conversion of lignin [21,27,34]; 57 wt \% methanol soluble oil was reported from reductive conversion of kraft lignin in methanol at $320{ }^{\circ} \mathrm{C}$ and $8 \mathrm{~h}$ reaction time. ${ }^{21}$ Oregui-Bengoechea reported maximum oil yield of 65 wt \% from conversion of rice-straw lignin in ethanol/formic acid solution over sulfated alumina-supported NiMo catalyst at higher temperature and reaction time of $340{ }^{\circ} \mathrm{C}$ and $6 \mathrm{~h}^{34}$

To assess the sulfidation state of the non-presulfided catalyst after reaction, an experiment was made at $310{ }^{\circ} \mathrm{C}$ using the
Table 1. Results from Conversion of $\mathrm{H}-\mathrm{LS}^{a}$

\begin{tabular}{|c|c|c|c|c|c|c|}
\hline entry & $\begin{array}{l}\text { catalyst: } \\
\text { presulfided/ } \\
\text { oxide }\end{array}$ & $\begin{array}{l}\text { catalyst } \\
\text { mass }[\mathrm{g}]\end{array}$ & $\begin{array}{l}\text { reaction } \\
\text { time }[\mathrm{h}]\end{array}$ & $T\left[{ }^{\circ} \mathrm{C}\right]$ & $\begin{array}{l}\text { oil yield } \\
\text { (wt \%) }\end{array}$ & $\begin{array}{c}\text { solid } \\
\text { yield } \\
\text { (wt \%) }\end{array}$ \\
\hline 1 & oxide & 1 & 3 & 310 & 67 & 38 \\
\hline 2 & noncatalytic & 0 & 3 & 310 & 26 & 77 \\
\hline $3^{b}$ & oxide & 1 & 3 & 310 & 45 & 64 \\
\hline 4 & noncatalytic & 0 & 3 & 260 & 17 & 81 \\
\hline 5 & oxide & 1 & 3 & 260 & 29 & 72 \\
\hline 6 & presulfided & 1 & 3 & 260 & 46 & 56 \\
\hline $7^{c}$ & oxide & 0.5 & 3 & 310 & 76 & 24 \\
\hline $8^{c}$ & presulfided & 0.5 & 3 & 310 & 76 & 25 \\
\hline $9^{d}$ & presulfided & 1 & 3 & 260 & 44 & 51 \\
\hline 10 & presulfided & 1 & 3 & 290 & 53 & 45 \\
\hline 11 & presulfided & 1 & 3 & 300 & 62 & 40 \\
\hline 12 & oxide & 1 & 1 & 310 & 53 & 49 \\
\hline 13 & oxide & 1 & 2 & 310 & 61 & 42 \\
\hline 14 & oxide & 1 & 4 & 310 & 79 & 25 \\
\hline 15 & oxide & 0.5 & 3 & 310 & 57 & 47 \\
\hline 16 & oxide & 2 & 3 & 310 & 88 & 15 \\
\hline 17 & oxide & 3 & 3 & 310 & 87 & 16 \\
\hline $18^{e}$ & spent catalyst & NA & 3 & 310 & 65 & 35 \\
\hline $19^{f}$ & spent catalyst & NA & 3 & 310 & 61 & 36 \\
\hline
\end{tabular}

${ }^{a}$ Reaction condition: NiMo-I catalyst, $10 \mathrm{~g} \mathrm{H}-\mathrm{LS}, 100 \mathrm{~mL}$ ethanol, 26 bar $\mathrm{H}_{2}$ (loaded at RT). ${ }^{b}$ Experiment in $\mathrm{N}_{2}$ atmosphere $\left(8\right.$ bar $\mathrm{N}_{2}$ loaded at RT), ${ }^{c} 0.5 \mathrm{~g}$ catalyst, $5 \mathrm{~g}$ lignin, $50 \mathrm{~mL}$ solvent, ${ }^{d}$ With addition of $1 \mathrm{~mL}$ DMDS, ${ }^{e}$ Reusing catalyst from entry $1,{ }^{,}$Reusing catalyst from entry 18 .

homemade non-presulfided NiMo-II catalyst ( $0.5 \mathrm{~g}$ of catalyst, $5 \mathrm{~g}$ of H-LS, $50 \mathrm{~mL}$ of ethanol, $3 \mathrm{~h}$, no DMDS addition) and subsequently the TEM-EDX analysis of the spent NiMo-II catalyst was obtained. Moreover, the TEM-EDX analysis of fresh presulfided NiMo-II and spent presulfided NiMo-II after reaction $(0.5 \mathrm{~g}$ of catalyst, $5 \mathrm{~g}$ of H-LS, $50 \mathrm{~mL}$ of ethanol, 310 ${ }^{\circ} \mathrm{C}, 3 \mathrm{~h}$, no DMDS addition) were obtained as reference. The oil yields observed using NiMo-II catalyst in the nonpresulfided and presulfided forms were 79 and 81 wt \%, respectively, and were comparable with those obtained using non-presulfided and presulfided NiMo-I with similar catalyst, lignin and solvent loading (Table 1, entries 7 and 8).

The $\mathrm{MoS}_{2}$ slabs were clearly visible in the TEM images of the fresh presulfided NiMo-II (Figure 2a) and the spent presulfided NiMo-II (Figure 2b). Regarding the spent nonpresulfided NiMo-II (Figure 2, c), linear features were detected which were consistent with $\mathrm{MoS}_{2}$ slabs, however, in a less developed state compared to the presulfided NiMo-II catalyst samples. The EDX analysis of the spent non-presulfided NiMoII showed a homogeneous distribution of $\mathrm{Ni}, \mathrm{Mo}$ and $\mathrm{S}$ (shown in Figure 3). 10.0 wt \% sulfur was determined by ICP in the sulfided home-synthesized NiMo-II catalyst, which is sufficient to convert $\mathrm{Mo}$ and $\mathrm{Ni}$ atoms to the sulfided state. On the basis of the TEM and EDX results, we therefore conclude that the catalyst was sulfided in situ from the sulfur present in the structure of lignin. In some EDX images, local accumulation of $\mathrm{Ni}$ and $\mathrm{S}$ was observed (shown in the Supporting Information, Figure S1), which is most likely due to formation of $\mathrm{Ni}_{3} \mathrm{~S}_{2}$ along with NiMoS. ${ }^{35}$

The role of the catalyst was studied by conversion of H-LS in the absence of catalyst (Table 1, entry 2 ). The presence of the catalyst clearly promoted formation of the liquefied fragments as only 26 wt \% oil was obtained in noncatalytic condition compared to 67 wt \% with the catalyst. Conversely, 

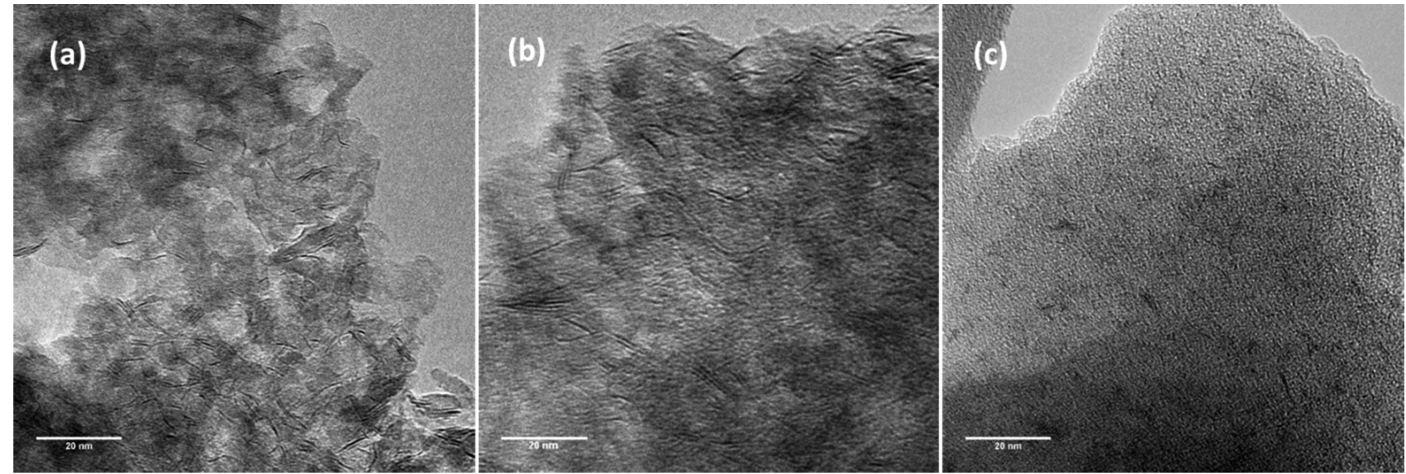

Figure 2. TEM images of (a) fresh presulfided NiMo-II, (b) spent presulfided NiMo-II, (c) spent non-presulfided NiMo-II. Reaction conditions: $0.5 \mathrm{~g}$ of NiMo-II catalyst, $5 \mathrm{~g}$ of H-LS, $50 \mathrm{~mL}$ of ethanol, 26 bar of $\mathrm{H}_{2}$ (loaded at RT), $3 \mathrm{~h}$.
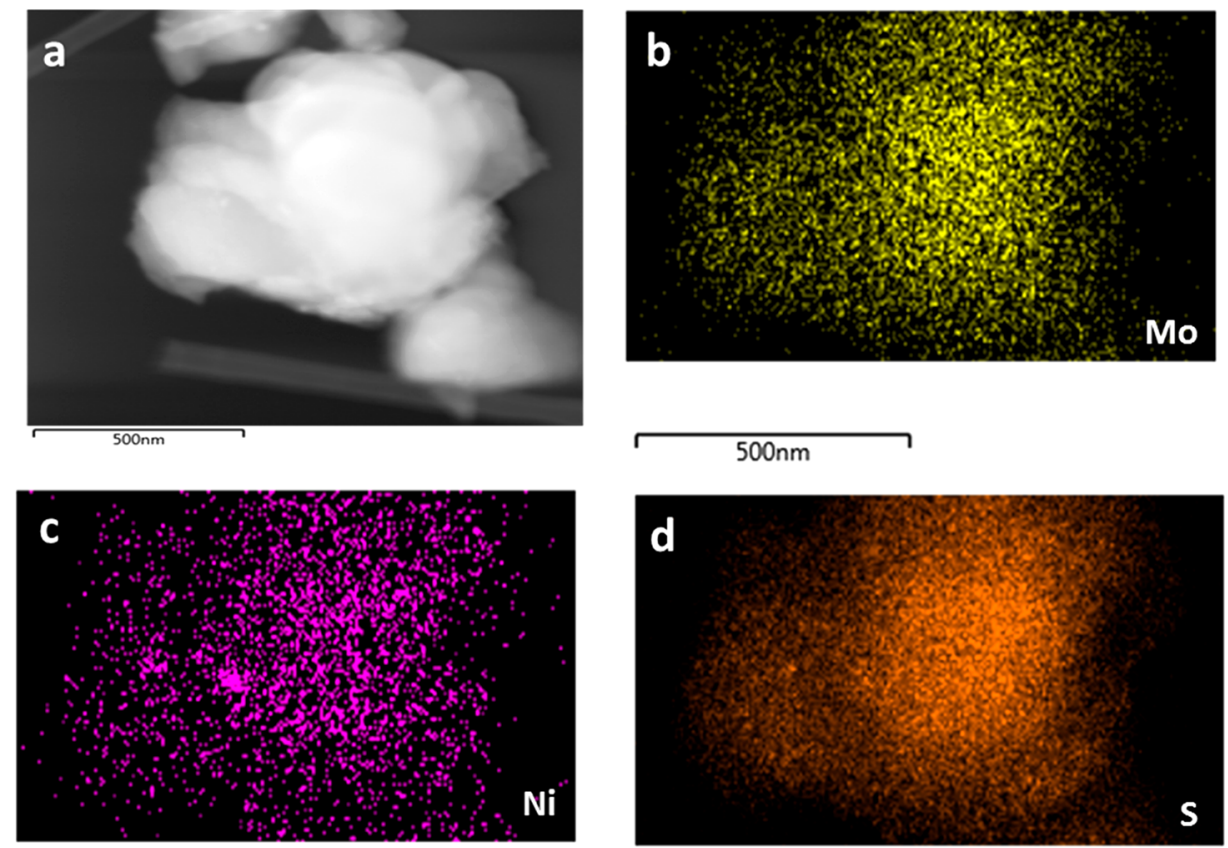

Figure 3. (a) TEM image of spent non-presulfided NiMo-II catalyst, EDX mapping of (b) Mo, (c) Ni, and (d) S in spent non-presulfided NiMo-II catalyst from reaction of $\mathrm{H}-\mathrm{LS}$ at $310^{\circ} \mathrm{C}$. Reaction conditions: $0.5 \mathrm{~g}$ of NiMo-II catalyst, $5 \mathrm{~g}$ of $\mathrm{H}-\mathrm{LS}, 50 \mathrm{~mL}$ of ethanol, 26 bar of $\mathrm{H}_{2}$ (loaded at $\mathrm{RT}), 3 \mathrm{~h}$.

the solid fraction was $77 \mathrm{wt} \%$ in the absence of the catalyst versus 38 wt $\%$ in the catalytic condition. The oil and solid fractions from noncatalytic and catalytic tests were comprehensively evaluated in order to determine the role of catalyst and differences in product distribution.

3.1.1. Evaluation of the Oil Fractions. The oil fractions were analyzed with GC-MS. The chromatograms and structures of the main compounds identified with the mass spectrometer are shown in Figure 4. Here it should be considered that only the compounds that were sufficiently volatile to pass through the column at the GC conditions were identified with the MS, and the GC analysis therefore only covers the lowest size range of the products. Guaiacol, alkylated guaiacols, and ethyl vanillate comprised the main identified compounds in the oil from the noncatalytic test (Table 1, entry 2, see Figure 4a). Guaiacol and alkyl substituted guaicols are expected compounds from degradation of spruce based lignin as this lignin is mainly composed of coniferyl alcohol units (G-Lignin). ${ }^{36}$ Formation of guaiacol and its variations can be attributed to the cleavage of $\beta$-O-4 bonds. $^{37}$ Formation of ethyl vanillate may take place by formation of vanillic acid from cleavage of ether bonds and esterification with ethanol. Noticeably, the identified compounds in the oil from catalytic conversion were different from the compounds in the absence of catalyst (Table 1, entry 1 , see Figure 4b). Three main groups of compounds were identified in the oil fraction obtained from the catalytic test using NiMo-I (Table 1, entry 1): alkyl phenols, alkoxy alkyl phenols and alkoxy alkyl benzenes. The selectivity to monooxygencontaining compounds in the catalytic oil was more than $50 \%$ (area basis), whereas all the compounds in the oil fraction from noncatalytic test contained at least two oxygen atoms. This implies a deoxygenation activity of the catalyst on the dioxygenated species. The presence of alkyl and alkyl ether bonds was pronounced in the monomers of the catalytic oil, most probably due to $\mathrm{C}$ - and $\mathrm{O}$ - alkylation with ethanol ${ }^{7}$ catalyzed over the $\mathrm{NiMo} / \mathrm{Al}_{2} \mathrm{O}_{3}$ catalyst. Horacek and coworkers $^{27}$ observed guaiacol and guaiacol derivatives from conversion of $5 \mathrm{wt} \%$ aqueous solution of lignosulfonate over an alumina supported NiMo catalyst at $320^{\circ} \mathrm{C}$, partially similar 

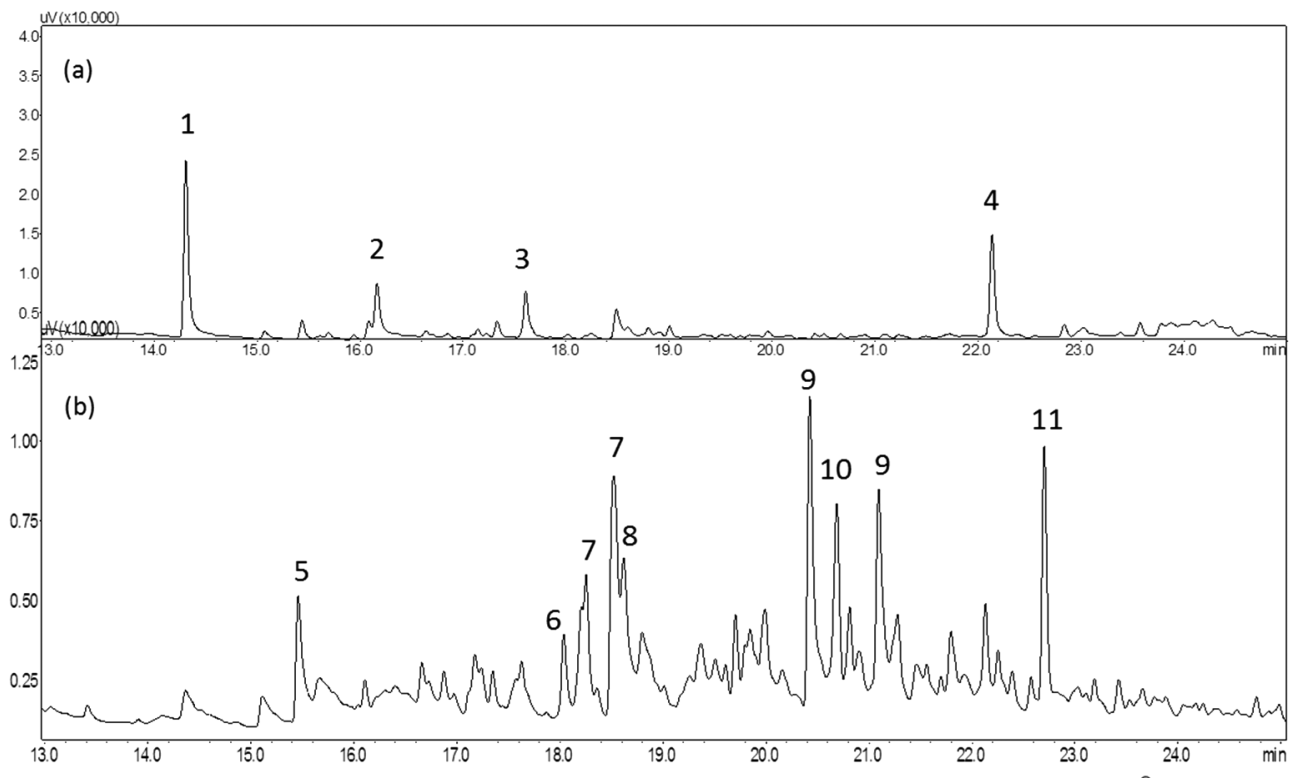<smiles>COc1ccccc1O</smiles>

1<smiles>CCOc1ccccc1O</smiles>

5<smiles>COc1cc(O)c(C)c(C)c1C</smiles><smiles>COc1cc(C)ccc1O</smiles><smiles>CCc1cccc(CC)c1O</smiles>

6

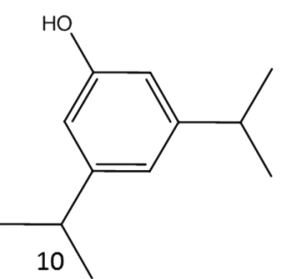<smiles>CCc1ccc(O)c(OC)c1</smiles>

3<smiles>COc1c(C)cc(C)cc1C</smiles><smiles>COc1c(C)c(C)c(OC)c(C)c1C</smiles><smiles>CCOC(=O)c1ccc(O)c(OC)c1</smiles><smiles>CCOc1ccc(CC)cc1OCC</smiles>

Figure 4. GC-MS analysis of the oil fractions from conversion of $\mathrm{H}-\mathrm{LS}$ at $310^{\circ} \mathrm{C}$ : (a) noncatalytic; (b) catalytic. Reaction conditions: $0 / 1 \mathrm{~g}$ of NiMo-I catalyst, $10 \mathrm{~g}$ of H-LS, $100 \mathrm{~mL}$ of ethanol, 26 bar of $\mathrm{H}_{2}$ (loaded at RT), $3 \mathrm{~h}$.

to the compounds observed in the noncatalytic oil in this work. The difference between the products observed in our catalytic oil and the catalytic oil in the work from Horacek et al. ${ }^{27}$ is ascribed to the role of ethanol compared to water in alkylation of reactive intermediate. ${ }^{7}$ It was assumed that saturation of aromatics did not take place since aliphatic cyclic compounds were not detected by GC analysis in the oil samples.

Moreover, the oil fractions from noncatalytic and catalytic conversion of $\mathrm{H}$-LS at $310^{\circ} \mathrm{C}$ were qualitatively analyzed with $\mathrm{GC} \times \mathrm{GC}$ analysis for identification of the main compound groups in the oil fractions (Figure 5). Guaiacol and alkyl guaiacols (methyl-, ethyl-, and propyl-substituted guaiacol) and catechol and alkyl catechols (methyl- and ethyl-substituted catechols) were the major identified compounds in the oil fraction obtained in the noncatalytic condition, whereas alkyl phenols, alkyl benzenes, and alkyl catechols were identified compound groups in the catalytic oil. Ethanol incorporation in form of alkylation was clearly observed over the catalyst, where bis and tert alkyl compounds were detected. Oxygen-free compounds such as alkyl benzene were only detected in the oil from catalytic conversion of H-LS. Deoxygenation and alkylation reactions in the presence of the catalyst were therefore confirmed by GC $\times$ GC, which is consistent with the GC-MS results. Vanillic acid derivatives were the other identified group in noncatalytic condition, while the intensities corresponding to this group considerably decreased in the catalytic oil, presumably by the deoxygenation activity of the catalyst in removing the carboxyl groups. Moreover, vanillin derivatives with a low intensity were detected in the oil from noncatalytic condition only.

The SEC analysis of the noncatalytic and catalytic oils are shown in Figure 6 and the SEC of H-LS is shown for comparison. The retention times of phenol, GGGE and tannic acid are further shown as standards. According to the SEC results, H-LS is highly degraded to liquefied compounds, however, the conversion of H-LS over the NiMo catalyst did not result in formation of compounds with a higher degree of depolymerization as both oil fractions had the same retention time range. The oil from noncatalytic test showed a bimodal elution, while the oil from the catalytic condition had a more 


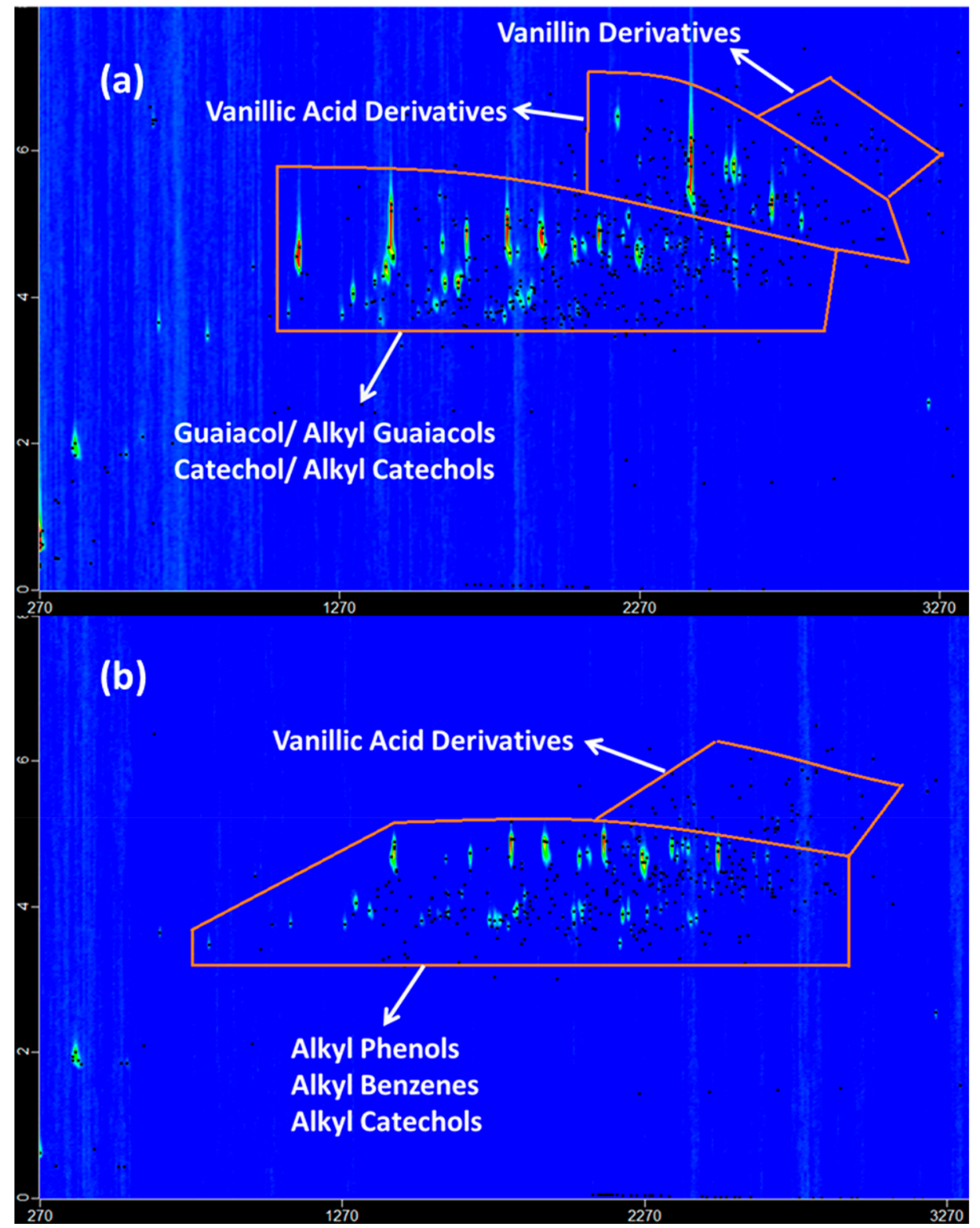

Figure 5. GC $\times$ GC analysis of the oil fractions from (a) noncatalytic and (b) catalytic condition at $310^{\circ} \mathrm{C}$. Reaction conditions: $0 / 1 \mathrm{~g}$ of NiMo-I catalyst, $10 \mathrm{~g}$ of $\mathrm{H}-\mathrm{LS}, 100 \mathrm{~mL}$ of ethanol, 26 bar of $\mathrm{H}_{2}$ (loaded at RT), $3 \mathrm{~h}$.

uniform molecular weight distribution. The main peaks in both oil samples had elution times within the range of dimers to oligomers, however, the catalytically produced oil had a greater fraction of larger compounds. The formation of a higher fraction of monomers perhaps requires higher reaction temperature to break the highly stable $\mathrm{C}-\mathrm{C}$ bonds and may then lead to too light products. The potential reasons for the similar sizes of the oil fractions are elaborated later with the mechanism of the lignin degradation.

In order to get a better insight into the functional groups in the oil fractions HSQC NMR was utilized. The NMR analysis of the oil fractions from noncatalytic and catalytic reactions over NiMo-I at $310{ }^{\circ} \mathrm{C}$ are shown in Figure 7 . The signals corresponding to the aliphatic and aromatic regions and the side chains are specified according to the literature. ${ }^{38,39}$ The prominent interconnecting units in the structure of lignin such as $\beta-\mathrm{O}-4$ and $\alpha-\mathrm{O}-4$ were not detected, indicating that the degradation in the absence and presence of catalyst perhaps resulted in the cleavage of these bonds. Compared to the noncatalytic oil, a pronounced decrease in methoxy protons $(\delta \mathrm{C} / \delta \mathrm{H} 56.2 / 3.75)$ relative to the aromatic protons was observed in the catalytic oil. In agreement with the GC-MS results, this indicates the catalytic hydrogenolysis and deoxygenation of methoxy groups. Additionally, 9 times more $\mathrm{CH}_{4}$ was evolved in the gas phase from the catalytic test which can partially be from hydrogenolysis of $-\mathrm{OCH}_{3}$ to $\mathrm{CH}_{4}$, along with solvent decomposition. A decrease in alcohol neighboring $-\gamma$-protons $(\delta \mathrm{C} / \delta \mathrm{H} 62.9 / 3.76,61.3 / 4.27)$, was observed in catalytically produced oil. This indicated the removal of the hydroxyl group on the aliphatic carbon in the presence of the catalyst. Higher intensities in the aliphatic region were detected in the oil from catalytic conversion which corresponds to $\mathrm{CH}_{3} / \mathrm{CH}$ in $\alpha$ position connected to an aromatic ring and is consistent with the observed ethanol alkylation reactions catalyzed over the NiMo catalyst. 


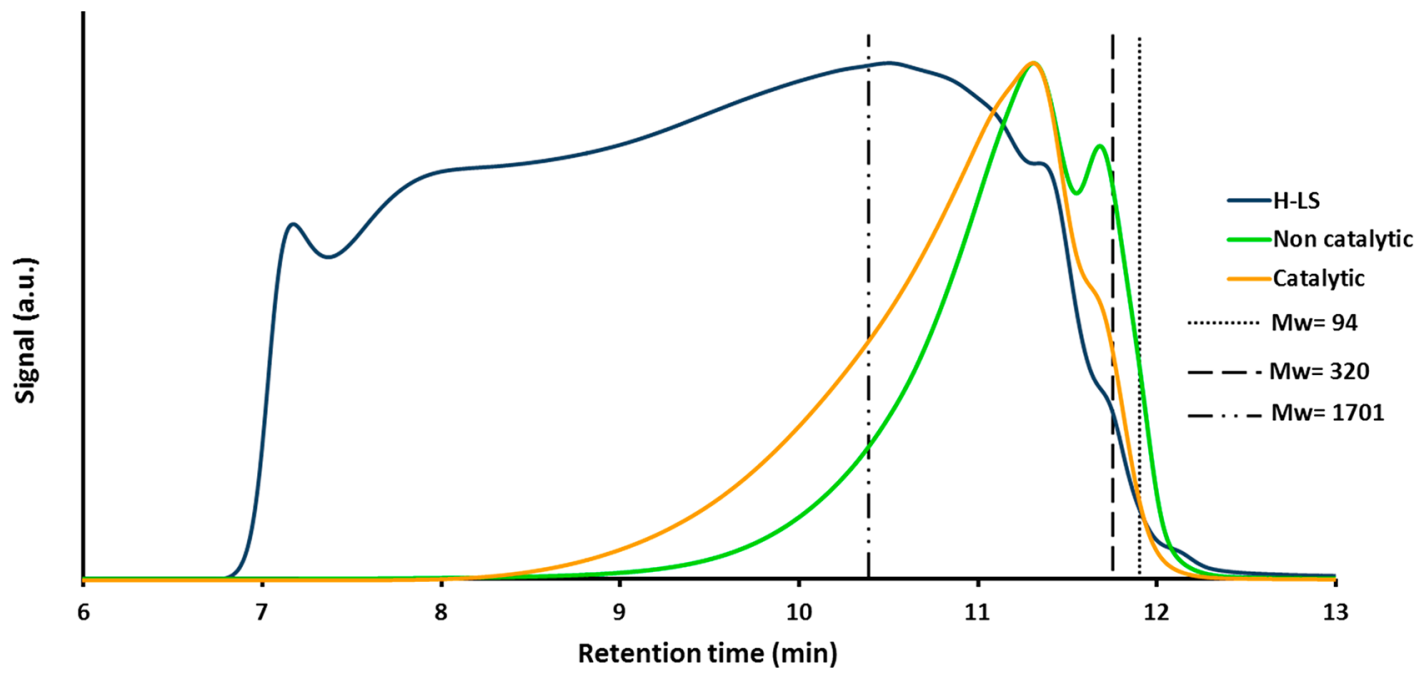

Figure 6. SEC analysis of H-LS, oils from noncatalytic and catalytic conversion at $310^{\circ} \mathrm{C}$. Reaction conditions: $0 / 1 \mathrm{~g}$ of NiMo-I catalyst, $10 \mathrm{~g}$ of $\mathrm{H}-$ LS, $100 \mathrm{~mL}$ of ethanol, 26 bar of $\mathrm{H}_{2}$ (loaded at RT), $3 \mathrm{~h}$.

The elemental analysis of the H-LS and the oil samples is shown in Table 2. The higher heating values (HHVs) were calculated using the Dulong formula. ${ }^{40}$ The oxygen content of the noncatalytic oil fraction (Table 2, entry 2) was $23.2 \mathrm{wt} \%$, which compared to 30.8 wt \% in H-LS indicated that the deoxygenation took place even in the absence of catalyst. This is in agreement with the observations of Nielsen et al., ${ }^{41}$ where deoxygenation was reported in noncatalytic conversion of lignin obtained from enzymatically hydrolyzed straw, in ethanol at $250-450{ }^{\circ} \mathrm{C}$. A higher degree of deoxygenation was observed over NiMo-I catalyst (Table 2, entry 3), where the oxygen content decreased to $11.4 \mathrm{wt} \%$. The HHV of the oil obtained over NiMo-I catalyst was calculated to be 36.5 $\mathrm{MJ} / \mathrm{kg}$, which is similar to that of butanol (HHV of $36.6 \mathrm{MJ} /$ $\mathrm{kg}) .{ }^{42}$ Surprisingly, the sulfur content of the oil from the noncatalytic test was only 0.3 wt \%, measured by ICP analysis, which was lower than in the oil from catalytic test, $0.4 \mathrm{wt} \%$. However, the sulfur content of the catalytic oil can be reduced to $0.1 \mathrm{wt} \%$ by prolonging the reaction time to $4 \mathrm{~h}$, which is elaborated later.

The role of hydrogen on degradation of lignin was studied by catalytic conversion of $\mathrm{H}-\mathrm{LS}$ in $\mathrm{N}_{2}$ atmosphere ( 8 bar at RT). Here, oil and solid yields of 45 and 64 wt \% were detected, respectively (Table 1 , entry 3 ). The oil yield in $\mathrm{N}_{2}$ atmosphere was lower than the oil yield in $\mathrm{H}_{2}$ atmosphere $(45$ vs 67 wt \%). Similarly, Narani et al. ${ }^{21}$ observed 22 wt \% methanol soluble oil from conversion of kraft lignin over NiMoS/AC in the absence of $\mathrm{H}_{2}$, while the oil yield increased to $53 \mathrm{wt} \%$ in the presence of 35 bar $\mathrm{H}_{2}$ (loaded at RT). The elemental composition of the oil in $\mathrm{N}_{2}$ atmosphere however showed similar features to the oil from $\mathrm{H}_{2}$ (Table 2, entry 4). It is speculated that in situ ethanol-derived hydrogen can be involved in hydrogenolysis and reductive deoxygenation reactions. The formation of hydrogen from ethanol in nitrogen atmosphere was confirmed by GC analysis, with the hydrogen partial pressure of 4.9 bar (the cold pressure of the autoclave was 21 bar). The NMR analysis (shown in the Supporting Information, Figure S2) indicated that the catalyst was capable of demethoxylation under nitrogen pressure, to the same extent as under hydrogen pressure. However, the decrease of $\gamma$ protons did not progress to the same extent in nitrogen atmosphere, perhaps due to the lower partial pressure of hydrogen. Therefore, it is concluded that higher partial pressure of hydrogen affects the liquefaction reactions positively likely by deoxygenation and stabilization of reactive radicals.

On the basis of the results from characterization of the oil fractions using different analytical techniques, the following mechanism is suggested: The similar molecular weight distribution ranges observed by SEC analysis of the oil fractions from noncatalytic and catalytic conditions indicates that the depolymerization reactions are possibly not affected by the catalyst. Moreover, the HSQC NMR analysis of the oils confirmed absence of prominent interconnecting units in the structure of lignin such as $\beta-\mathrm{O}-4$ in noncatalytic and catalytic conditions, and aligned with SEC results indicates that degradation reactions of $\mathrm{H}$-LS possibly occur via thermal cracking and ethanolysis of the more susceptible bonds. Highly reactive intermediates produced from depolymerization undergo fast condensation reactions, unless the reactivity is suppressed by end-capping reactions. ${ }^{43}$ In the presence of the catalyst, stabilization of radical fragments takes place via ethanol alkylation reactions, resulting in stabilization of radicals and therefore higher liquefaction yields. ${ }^{7}$ The limited formation of monomeric species suggests that the dimers and oligomers formed in the degradation have interconnecting bonds that cannot be broken at the applied reaction conditions, even in the presence of a catalyst. An additional role of the catalyst is deoxygenation reactions via reductive removal of hydroxyl and methoxy groups, which is favorable for production of fuels.

3.1.2. Evaluation of the Solid Fractions. The solid residue in the absence of catalyst consisted of large agglomerated lumps, whereas the solid residue from the catalytic reaction had much smaller particles of more uniform size, presumably due to grinding action of the catalyst particles on the char under the stirring and also lower degree of condensation. The physical appearance of the solid fractions from noncatalytic and catalytic conditions (Table 1, entries 1 and 2) is shown in the Supporting Information, Figure S3. The elemental composition of $\mathrm{H}-\mathrm{LS}$ and the solid residues from noncatalytic and catalytic conversion of H-LS is shown in Table 3. The solid from noncatalytic test had a higher carbon content (76.4 wt \%) than the solid from catalytic conversion (65.3 wt \%) 

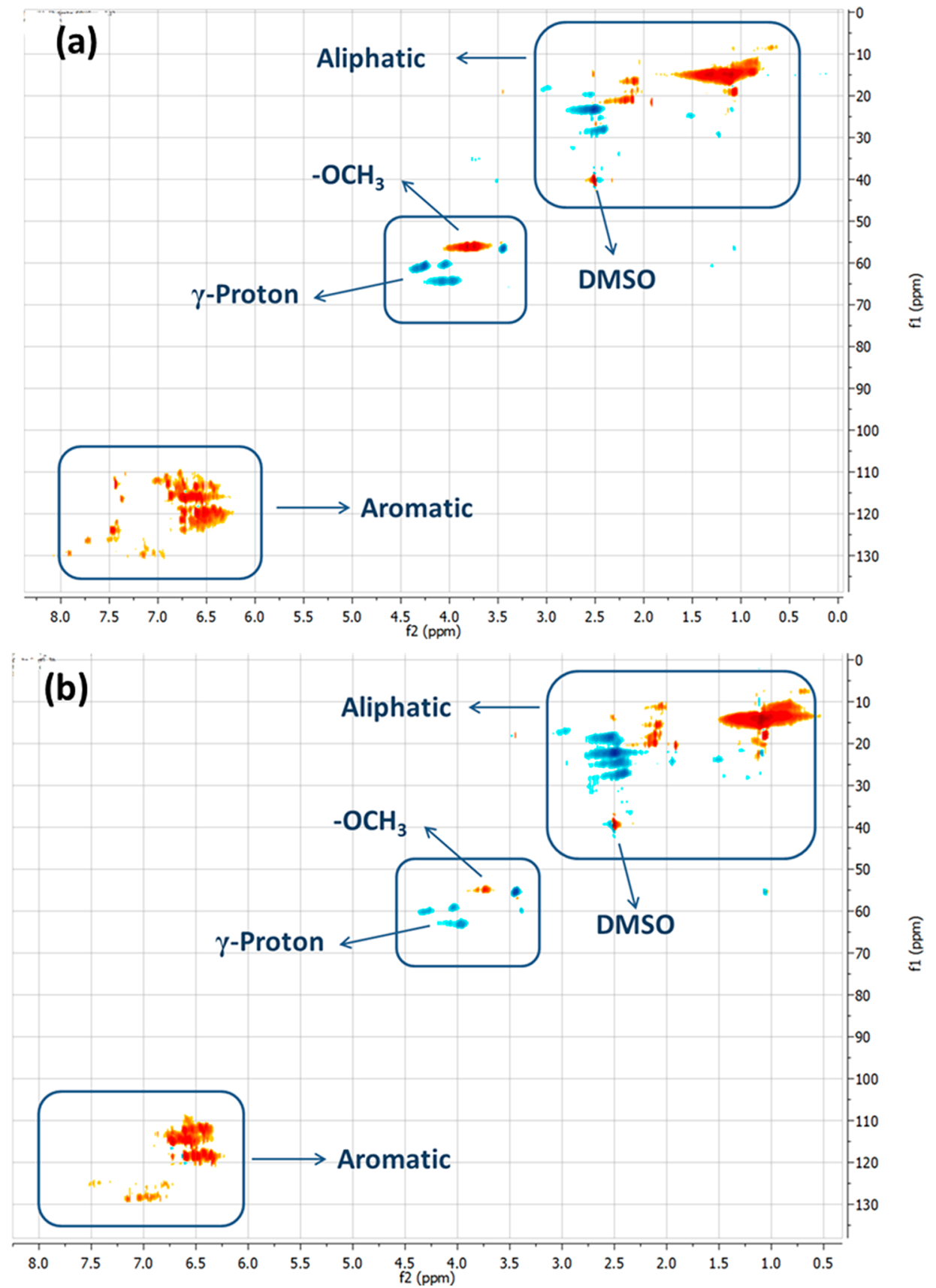

Figure 7. HSQC NMR of the oil fractions from (a) noncatalytic oil and (b) catalytic condition at $310{ }^{\circ} \mathrm{C}$. Reaction conditions: $0 / 1 \mathrm{~g}$ of NiMo-I catalyst, $10 \mathrm{~g}$ of $\mathrm{H}-\mathrm{LS}, 100 \mathrm{~mL}$ of ethanol, 26 bar of $\mathrm{H}_{2}$ (loaded at RT), $3 \mathrm{~h}$.

Table 2. Elemental Analysis and the HHVs of H-LS and the Oil Fractions from Non-Catalytic and Catalytic Conversion of HLS at $310{ }^{\circ} \mathrm{C}^{a}$

$\begin{array}{cclccccccc}\text { entry } & \text { H-LS/oil } & \text { catalyst } & \mathrm{C}(\mathrm{wt} \%) & \mathrm{O}(\mathrm{wt} \%) & \mathrm{H}(\mathrm{wt} \%) & \mathrm{S}(\mathrm{wt} \%) & \text { atomic O/C } & \text { atomic H/C } & \mathrm{HHV}(\mathrm{MJ} / \mathrm{kg}) \\ 1 & \mathrm{H}-\mathrm{LS} & - & 61.1 & 30.8 & 4.4 & 3.1 & 0.38 & 0.86 & 21.4 \\ 2 & \text { oil } & \text { noncatalytic } & 69.9 & 23.2 & 6.7 & 0.3 & 0.25 & 1.14 & 29.0 \\ 3 & \text { oil } & \text { NiMo-I } & 80.1 & 11.4 & 8.0 & 0.4 & 0.11 & 1.20 & 36.5 \\ 4^{b} & \text { oil } & \text { NiMo-I } & 79.9 & 11.3 & 8.4 & 0.3 & 0.11 & 1.27 & 37.1\end{array}$

${ }^{a}$ Reaction conditions: $0 / 1 \mathrm{~g}$ of NiMo-I catalyst, $10 \mathrm{~g}$ of H-LS, $100 \mathrm{~mL}$ of ethanol, 26 bar of $\mathrm{H}_{2}$ (loaded at RT) except for the test in $\mathrm{N}_{2}$ atmosphere, 3 h. ${ }^{b}$ Oil produced in $\mathrm{N}_{2}$ atmosphere ( 8 bar $\mathrm{N}_{2}$ loaded at $\mathrm{RT}$ ).

whereas the chemical composition of the solid from catalytic condition possessed very similar composition to H-LS, except for the sulfur content (Table 3, entry 1). Getting insight into the molecular weight distribution of the solid phases was not achievable due to their insoluble character in 90/10 wt \% $\mathrm{DMSO} /$ water containing $0.05 \mathrm{M} \mathrm{LiBr}$ (solvent used for SEC analysis, in which H-LS is completely soluble). Therefore, it was concluded that both solid fractions were produced from 
Table 3. Elemental Analysis and the HHVs of H-LS and the Solid Fractions from Non-Catalytic and Catalytic Conversion of H-LS at $310{ }^{\circ} \mathrm{C}^{a}$

\begin{tabular}{|c|c|c|c|c|c|c|c|c|c|}
\hline entry & H-LS/solid & catalyst & C (wt \%) & O (wt \%) & $\mathrm{H}$ (wt \%) & S (wt \%) & atomic $\mathrm{O} / \mathrm{C}$ & atomic $\mathrm{H} / \mathrm{C}$ & $\mathrm{HHV}(\mathrm{MJ} / \mathrm{kg})$ \\
\hline 1 & H-LS & - & 61.1 & 30.8 & 4.4 & 3.1 & 0.38 & 0.86 & 21.4 \\
\hline 2 & solid & noncatalytic & 76.4 & 17.8 & 4.8 & 0.9 & 0.17 & 0.75 & 29.5 \\
\hline 3 & solid & NiMo-I & 65.3 & 30.0 & 4.7 & N.A & 0.34 & 0.87 & 17.8 \\
\hline
\end{tabular}

${ }^{a}$ Reaction condition: 0/1 g of NiMo-I catalyst, $10 \mathrm{~g}$ of H-LS, $100 \mathrm{~mL}$ of ethanol, 26 bar of $\mathrm{H}_{2}$ (loaded at RT), $3 \mathrm{~h}$.

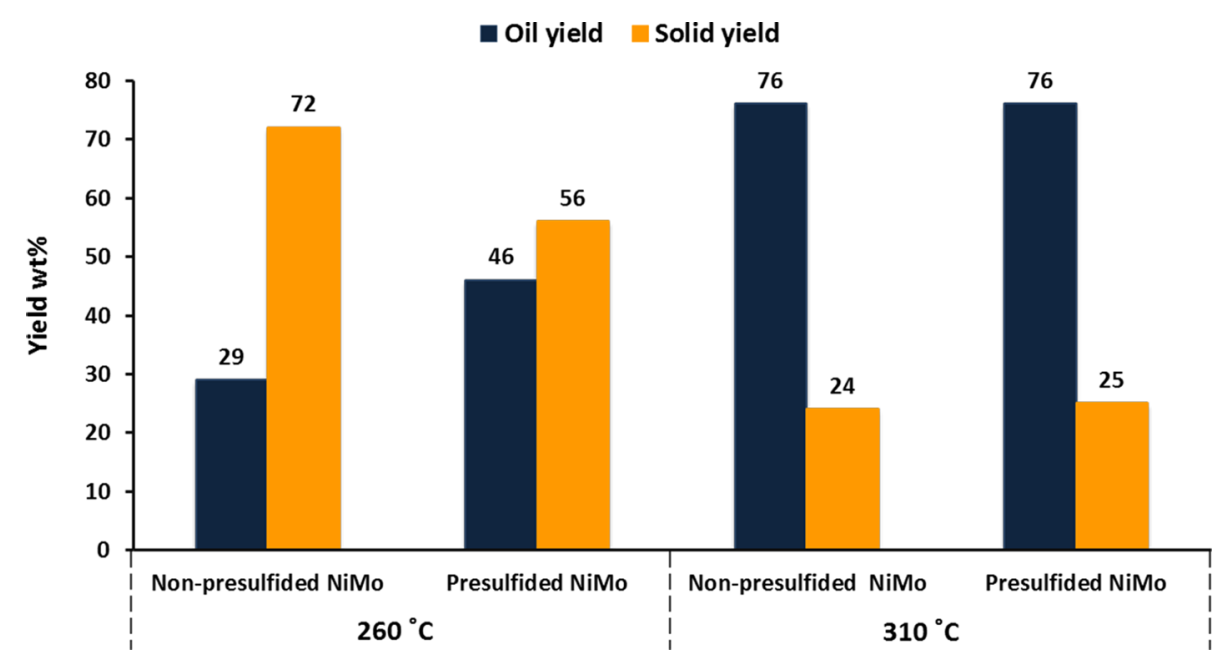

Figure 8. Oil and solid yields from degradation of H-LS with non-presulfided and presulfided NiMo-I at 260 and $310^{\circ} \mathrm{C}$. Loading at $260{ }^{\circ} \mathrm{C}: 1 \mathrm{~g}$ of catalyst, $10 \mathrm{~g}$ of H-LS, and $100 \mathrm{~mL}$ of ethanol. Loading at $310^{\circ} \mathrm{C}: 0.5 \mathrm{~g}$ of catalyst, $5 \mathrm{~g}$ of H-LS, and $50 \mathrm{~mL}$ of ethanol. For both: $26 \mathrm{bar}$ of $\mathrm{H}_{2}$ (loaded at RT), $3 \mathrm{~h}$.

condensation reactions. The higher oxygen content in the solid from catalytic condition compared to the noncatalytic solid suggests that it probably experienced a lower degree of condensation.

3.2. Effect of Catalyst Presulfidation on Products. As the TEM-EDX analysis suggest an in situ sulfidation, it is relevant to evaluate the impact of presulfiding the catalyst on the products. To this end, a number of tests were conducted with or without presulfidation of NiMo-I at 260 and $310{ }^{\circ} \mathrm{C}$ (results are shown in Figure 8). H-LS was tested in a noncatalytic reaction at $260{ }^{\circ} \mathrm{C}$ as a benchmark to compare noncatalytic and catalytic results at this temperature. Without catalyst, oil and solid yields of 17 and $81 \mathrm{wt} \%$ were obtained at $260{ }^{\circ} \mathrm{C}$ (Table 1 , entry 4 ). By addition of catalyst at $260{ }^{\circ} \mathrm{C}$ in the oxide form (Table 1 , entry 5 ), the oil yield increased to 29 wt $\%$, while the solid yield decreased to 72 wt \%. Moreover, by reaction of $\mathrm{H}$-LS over presulfided NiMo at $260{ }^{\circ} \mathrm{C}$ (Table 1, entry 6) the oil yield increased to $46 \mathrm{wt} \%$, and the solid yield decreased to $56 \mathrm{wt} \%$, which indicated that presulfidation of $\mathrm{NiMo}$ at $260{ }^{\circ} \mathrm{C}$ was advantageous to acquire higher catalytic activity.

At $310{ }^{\circ} \mathrm{C}$, the oil yield was 76 wt $\%$ over both the oxide and sulfide catalyst (Table 1, Entry 7 and 8 , respectively) and the solid yields were also similar of above 25 wt \% (Figure 8 ). It was therefore concluded that opposite to the tests at $260{ }^{\circ} \mathrm{C}$, there was no effect in terms of the oil and solid yields at 310 ${ }^{\circ} \mathrm{C}$ over non-presulfided and presulfided catalyst. In the experiments at $310{ }^{\circ} \mathrm{C}$, the loading of catalyst, lignin, and solvent were halved in order to avoid overpressure when using the presulfided NiMo $(0.5 \mathrm{~g}$ of catalyst, $5 \mathrm{~g}$ of H-LS, $50 \mathrm{~mL}$ of ethanol). It is interesting to observe that the oil yields increased under these conditions (compared to $67 \mathrm{wt} \%$ in standard reaction condition), which probably was due to higher partial pressure of hydrogen and also the variations in the density of supercritical ethanol and solubility of lignin. The oil fractions from non-presulfided and presulfided NiMo tests at $310{ }^{\circ} \mathrm{C}$ were analyzed with GC-MS analysis. The identified monomers and the selectivity were very similar (shown in Supporting Information, Table S1). However, the gas phase analysis indicated a major difference, where larger amount of gaseous products were formed for the presulfided catalyst (shown in Figure 9). The concentration of ethane in the gas phase from the test using the presulfided NiMo was more than twice of that in the gas phase from reaction over the nonpresulfided catalyst. A similar trend was observed for all gases

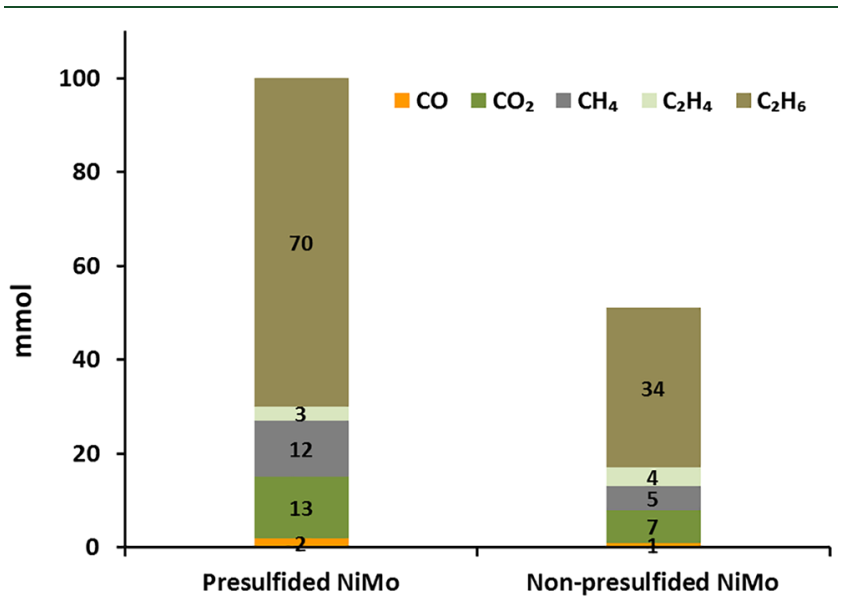

Figure 9. Gas phase analysis from conversion of H-LS over nonpresulfided and presulfided catalyst at $310{ }^{\circ} \mathrm{C}$. Reaction conditions: $0.5 \mathrm{~g}$ of NiMo-I catalyst, $5 \mathrm{~g}$ of H-LS, $50 \mathrm{~mL}$ of ethanol, 26 bar of $\mathrm{H}_{2}$ (loaded at RT), $3 \mathrm{~h}$. 


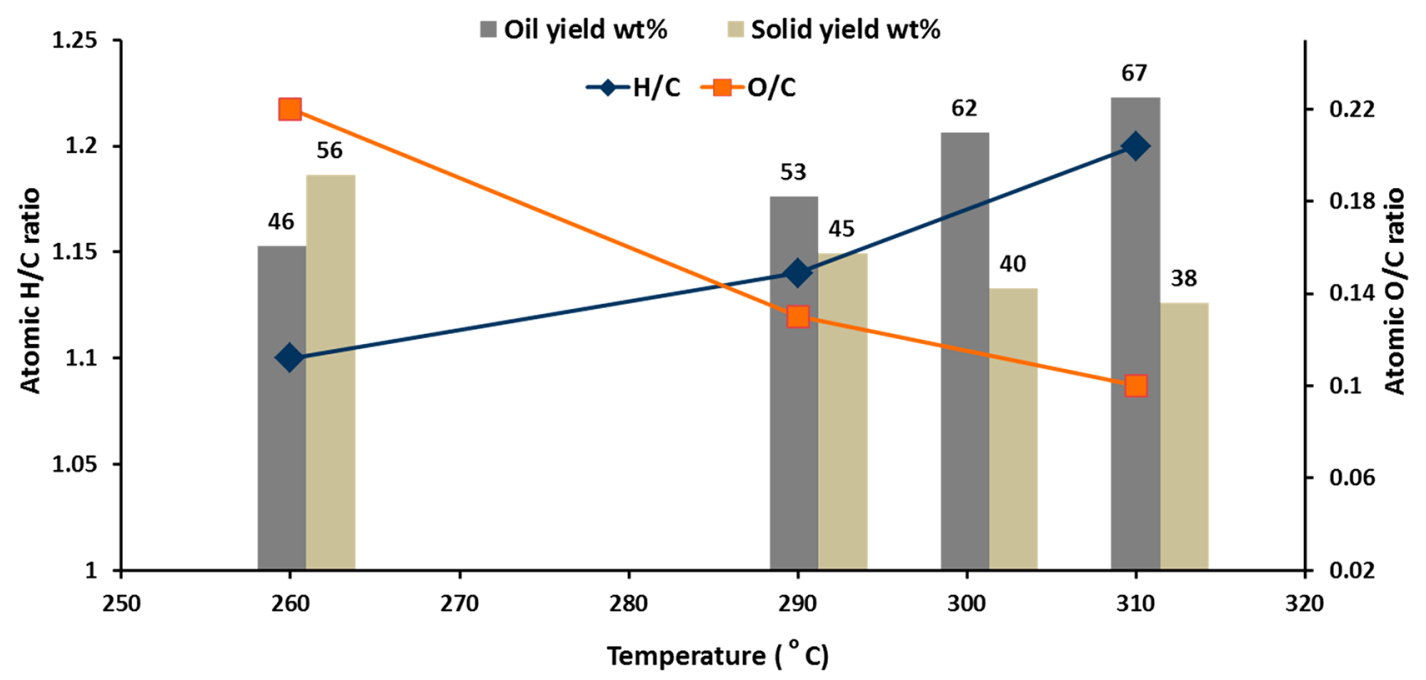

Figure 10. Oil and solid yields and atomic $\mathrm{H} / \mathrm{C}$ and $\mathrm{O} / \mathrm{C}$ ratios as a function of temperature. Reaction conditions: $1 \mathrm{~g}$ of NiMo-I catalyst, $10 \mathrm{~g}$ of $\mathrm{H}-\mathrm{LS}, 100 \mathrm{~mL}$ of ethanol, 26 bar of $\mathrm{H}_{2}$ (loaded at RT), $3 \mathrm{~h}$.

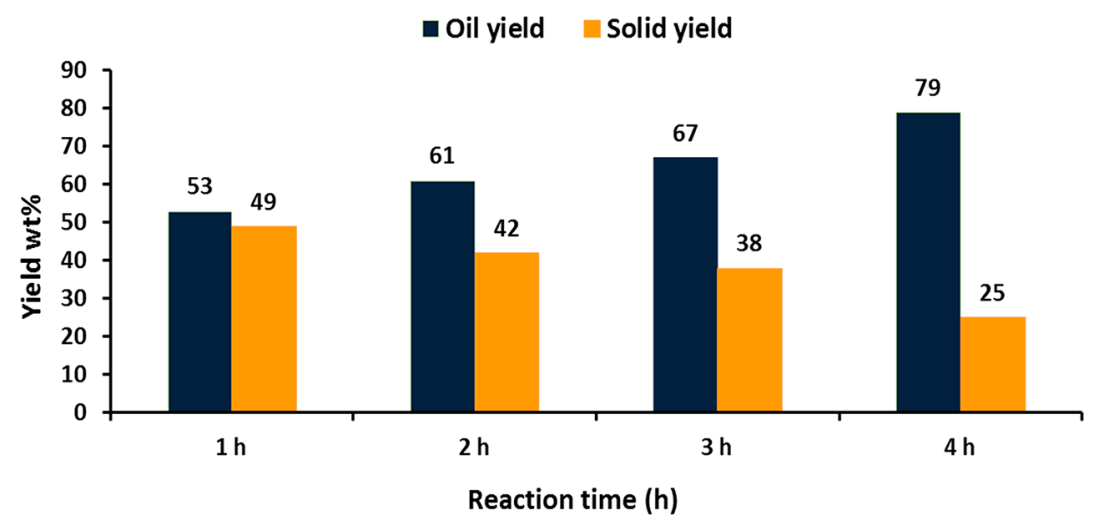

Figure 11. Oil and solid yields as a function of reaction time. Reaction conditions: $1 \mathrm{~g}$ of NiMo-I catalyst, $10 \mathrm{~g}$ of $\mathrm{H}-\mathrm{LS}, 100 \mathrm{~mL}$ of ethanol, $26 \mathrm{bar}$ of $\mathrm{H}_{2}$ (loaded at RT).

except for $\mathrm{C}_{2} \mathrm{H}_{4}$, which was converted over the presulfided catalyst to the alkane form $\left(\mathrm{C}_{2} \mathrm{H}_{6}\right)$. This was consistent with the rapid initial pressure increase over the presulfided catalyst. This initial gas formation most likely occurred from the solvent and stopped when the catalyst surface was partially covered with the lignin decomposition products. For the nonpresulfided catalyst, however, the sulfidation and initial lignin breakdown occurred simultaneously and therefore much less active free sites were available for solvent consumption in the early stages of the experiment.

Since in situ sulfidation of the oxide precursor does occur, the effect of presulfidation could suggest that the sulfide phase is the active form of the catalyst. At $260{ }^{\circ} \mathrm{C}$, the in situ sulfidation generating the active phase may occur with a significant delay in the $3 \mathrm{~h}$ reaction time, and therefore presulfidation is beneficial, but at $310{ }^{\circ} \mathrm{C}$ in situ sulfidation is kinetically fast enough that presulfidation is without substantial effect. Hereafter, the catalytic experiments at $310{ }^{\circ} \mathrm{C}$ were conducted using NiMo-I catalyst without presulfidation, unless specified.

The presence of a sulfur source in catalytic conversions using NiMo and CoMo catalysts is required in order to maintain catalyst activity. According to Mortensen et al. ${ }^{29}$ when hydrodeoxygenation of phenol takes place over NiMoS catalyst, both $\mathrm{H}_{2} \mathrm{~S}$ and $\mathrm{H}_{2} \mathrm{O}$ compete for the catalyst active sites $^{29}$ and in the absence of sulfur, the edge sulfur atoms can be replaced by oxygen. In a test, $1 \mathrm{~mL}$ of DMDS was added to the reactor for conversion of H-LS over presulfided NiMo-I at $260{ }^{\circ} \mathrm{C}$ (Table 1 , entry 9) to ensure sufficient partial pressure of $\mathrm{H}_{2} \mathrm{~S}$ inside the reactor. Almost similar results to the test in the absence of DMDS were observed, which indicated that the sulfidation state of catalyst can be maintained by organic sulfur from lignosulfonate or that the operating time was too short to lose significant amounts of sulfur from the catalyst.

3.3. Parameter Study. A parameter study on the reaction temperature, reaction time and catalyst loading was conducted in order to evaluate the role of each on the degradation of $\mathrm{H}$ LS.

3.3.1. Effect of the Reaction Temperature. The effect of reaction temperature on the degradation of H-LS was elaborated by including the reaction temperatures 290 (Table 1 , entry 10) and $300{ }^{\circ} \mathrm{C}$ (Table 1 , entry 11). The catalysts for the tests at 290 and $300{ }^{\circ} \mathrm{C}$ were presulfided to ensure catalytic activity. The oil and solid yields from conversion of $\mathrm{H}-\mathrm{LS}$ and the atomic $\mathrm{H} / \mathrm{C}$ and $\mathrm{O} / \mathrm{C}$ ratios are shown in Figure 10. The rise in the oil yield, increase in $\mathrm{H} / \mathrm{C}$ ratio and decrease in $\mathrm{O} / \mathrm{C}$ ratio shows the increase in lignin degradation and $\mathrm{HDO}$ reactions at higher temperature. The partial pressures of $\mathrm{CO}$ and $\mathrm{CO}_{2}$ in the gas phase from catalytic reaction at $260{ }^{\circ} \mathrm{C}$ were 1.08 and 1.7 bar, while at 310 
Table 4. Elemental Analysis of the Oil Fractions from Conversion of H-LS for Different Reaction Times ${ }^{a}$

\begin{tabular}{|c|c|c|c|c|c|c|c|}
\hline reaction time $[\mathrm{h}]$ & C (wt \%) & O (wt \%) & $\mathrm{H}($ wt \%) & $S(w t \%)$ & atomic $\mathrm{O} / \mathrm{C}$ & atomic $\mathrm{H} / \mathrm{C}$ & HHV (MJ/kg) \\
\hline 1 & 73.7 & 18.4 & 7.3 & 0.5 & 0.19 & 1.19 & 32.1 \\
\hline 2 & 78.8 & 13.2 & 7.5 & 0.5 & 0.12 & 1.15 & 35.0 \\
\hline 3 & 80.1 & 11.4 & 8.0 & 0.4 & 0.11 & 1.20 & 36.5 \\
\hline 4 & 80.6 & 11.2 & 8.0 & 0.1 & 0.10 & 1.20 & 36.7 \\
\hline
\end{tabular}

${ }^{a}$ Reaction conditions: $1 \mathrm{~g}$ of NiMo-I catalyst, $10 \mathrm{~g}$ of H-LS, $100 \mathrm{~mL}$ of ethanol, $26 \mathrm{bar} \mathrm{H}_{2}$ (loaded at RT)

${ }^{\circ} \mathrm{C}$ the partial pressures were 1.4 and 2.3 bar, respectively, indicating the prominent role of temperature on cleavage of $\mathrm{C}-\mathrm{O}$ bond, decarbonylation and decarboxylation. The oil yield increased with a relatively higher rate when the temperature increased from 290 to $300{ }^{\circ} \mathrm{C}$. The temperature required for high rate of degradation and cleavage of stable $\mathrm{C}-$ $\mathrm{C}$ and $\mathrm{C}-\mathrm{O}$ bonds depends on the type of biomass and treatment method. Yuan et $\mathrm{al}^{44}$ observed an increase of the depolymerization over $5 \% \mathrm{Ru} / \mathrm{C}$ in acetone for kraft lignin when the reaction temperature increased from 250 to $275^{\circ} \mathrm{C}$. However, they did not observe the same trend for organosolv lignin, as it originally had lower molecular weight distribution and much better solubility in ethanol at lower temperatures. ${ }^{44}$

Surprisingly, the SEC analysis of the oil fractions at 260 and $310{ }^{\circ} \mathrm{C}$ showed similar molecular weight distribution range (shown in the Supporting Information, Figure S4). Though the oil yield obtained at $310^{\circ} \mathrm{C}$ was higher than the yield at 260 ${ }^{\circ} \mathrm{C}$, the degree of depolymerization is limited to the specific molecular weight distribution. These observations indicate that at higher temperatures more degradation occurred, however, the degradation progressed only to a certain size range centered in the dimers to oligomers, and little degradation to monomers took place.

3.3.2. Effect of the Reaction Time. The effect of reaction time was studied by tests lasting 1,2 , and $4 \mathrm{~h}$ at $310^{\circ} \mathrm{C}$ (Table 1 , entries 12-14) and comparing to the test in $3 \mathrm{~h}$. The oil and solid yields are shown in Figure 11. The oil yield increased from $53 \mathrm{wt} \%$ in $1 \mathrm{~h}$ reaction time to $79 \mathrm{wt} \%$ in $4 \mathrm{~h}$ while the solid yield decreased from $49 \mathrm{wt} \%$ after $1 \mathrm{~h}$ reaction to $25 \mathrm{wt}$ $\%$ after $4 \mathrm{~h}$.

The elemental analysis and the atomic $\mathrm{O} / \mathrm{C}$ and $\mathrm{H} / \mathrm{C}$ ratio in the oil fractions are presented in Table 4. The atomic O/C ratio gradually decreased by increasing the reaction time. The NMR analysis of the oil fractions indicated that demethoxylation occurred progressively (shown in the Supporting Information, Figure S5-S7). In addition, a gradual increase in the partial pressure of methane indicated that hydrogenolysis continued throughout the reaction. However, the decrease of the methoxy groups leveled off after $3 \mathrm{~h}$. The gas phase analysis indicated that the $\mathrm{CO}$ production was nearly constant at different reaction time and the $\mathrm{CO}_{2}$ production increased by increase of the reaction time from 1 to $2 \mathrm{~h}$, but flattened by further increase of the reaction time indicating that decarbonylation and decarboxylation reactions progressed in the early stages of the reactions. The sulfur content, determined by ICP analysis, decreased from $0.5 \mathrm{wt} \%$ after 1 $\mathrm{h}$ reaction to $0.1 \mathrm{wt} \%$ after $4 \mathrm{~h}$, which if compared to the lignosulfonate with $3.1 \mathrm{wt} \%$ sulfur content, indicates $97 \%$ sulfur removal in the oil fraction after $4 \mathrm{~h}$. This shows that sulfur is removed from the liquid product over time as expected since the NiMoS is an efficient HDS catalyst.

The oil fractions were analyzed by GC-MS in order to get insight on evolution of the liquefied monomers. In the oil fraction from the $1 \mathrm{~h}$ test, guaiacol and ethyl vanillate (shown in Figure 4, compounds no. 1 and 4) were the main compounds detected which shared similarities with the noncatalytic oil fraction. Almost similar compounds were detected in the oil fraction obtained after $2 \mathrm{~h}$. However, in the oil from $3 \mathrm{~h}$ reaction time, the guaiacol and ethyl vanillate peaks disappeared and peaks corresponding to alkyl phenols, alkoxy alkyl phenols, and alkoxy alkyl benzenes were detected instead (shown in Figure 4). Similar compounds were detected in the oil after $4 \mathrm{~h}$, indicating that demethoxylation and alkylation progressed over time. Narani et al. ${ }^{21}$ observed that in conversion of kraft lignin, by prolonging the reaction time from 4 to $8 \mathrm{~h}$, guaiacol and substituted guaiacols transformed to alkyl phenols while the oil yield increased from 40 to $82 \mathrm{wt} \%$. In our experiments 79 wt \% oil was achievable with a considerably shorter reaction time of $4 \mathrm{~h}$ and the oil is comprised mainly of alkyl phenolic and alkoxy alkyl benzene compounds. The molecular weight distribution of the oil fractions after 2,3 , and $4 \mathrm{~h}$ reaction time indicated a similar pattern (detected by SEC analysis), while the oil fraction from $1 \mathrm{~h}$ reaction time showed formation of slightly lower molecular weight oil (shown in the Supporting Information, Figure S8). Similar to the observations on the reaction temperature, it was observed that the molecular weight distribution of the oil did not decrease by increasing the reaction times and therefore further decrease in the molecular weight of the oil fraction may require more severe conditions compared to those employed.

3.3.3. Effect of the Catalyst Loading. The effect of catalyst mass was investigated by varying the loading of catalyst with a fixed amount of H-LS (10 g). The solid and oil yields are shown in Table 1 (entries 15-17). The oil yield increased from 57 to 88 wt \% by increasing the catalyst mass from 0.5 to $2 \mathrm{~g}$ and the solid yield decreased from 47 wt \% to 15 wt \%. However, by increasing the catalyst mass from 2 to $3 \mathrm{~g}$ no further increase of the oil yield was observed. At this stage, the conversion of the original lignin seems to have stopped and the remaining solid was likely a highly cross-linked char from e.g. repolymerization reactions and therefore the oil yield did not change further as this solid could not be converted. The SEC analysis showed almost similar elution pattern, except for the oil from $0.5 \mathrm{~g}$ catalyst test. This oil was composed of smaller molecular weight fractions (shown in the Supporting Information, Figure S9). Similar to what was observed by increasing the reaction temperature and reaction time, further degradation of dimers and oligomers to monomers did not occur even with the highest catalyst loading. This supports the proposed mechanism for lignin degradation.

3.4. Catalyst Reusability. Catalyst reusability is a critical factor for catalytic processes. The spent catalyst from catalytic conversion of H-LS was mixed with solid char residue. Separation of the catalyst from the char was not possible; therefore, the entire solid residue fraction from a standard experiment (Table 1, entry 1) was used as a catalyst for a subsequent experiment, without any pretreatment. The oil yields decreased slightly from $67 \mathrm{wt} \%$ to 65 and $61 \mathrm{wt} \%$, by 
reusing catalyst for the first and second time (Table 1, entries 18 and 19) which may be due to the loss of catalyst in workup procedure. Moreover, coke may have formed on the catalyst. Considering the reasonably high oil yields, it was concluded that the catalyst is reusable for at least two times without any pretreatment.

\section{CONCLUSION}

Lignosulfonate in the acid form was successfully degraded in the presence of alumina supported NiMo catalysts at temperature ranges of $260-310^{\circ} \mathrm{C}$ in ethanol. The presence of the catalyst resulted in a considerable increase of the liquefied fractions, which was attributed to stabilization of reactive compounds with reductive ethanol incorporation over catalytic sites. $67 \mathrm{wt} \%$ oil yield was obtained from conversion of $\mathrm{H}-\mathrm{LS}$ at standard reaction condition at $310{ }^{\circ} \mathrm{C}(1 \mathrm{~g}$ of catalyst: $10 \mathrm{~g}$ of $\mathrm{H}-\mathrm{LS}$ : $100 \mathrm{~mL}$ of solvent, Initial $\mathrm{H}_{2}$ loading of 26 bar, $3 \mathrm{~h}$ ). It was observed that at $310{ }^{\circ} \mathrm{C}$, in situ activation of the catalyst to $\mathrm{NiMoS}$ was achievable by reaction with sulfur from the lignosulfonate. However, presulfidation of the catalyst was required at lower temperatures e.g. $260{ }^{\circ} \mathrm{C}$. The yield of liquefied fraction increased to $88 \mathrm{wt} \%$ by doubling the catalyst loading at $310{ }^{\circ} \mathrm{C}$. The reusability of the catalyst without any pretreatment was confirmed for at least two times with only a minor loss in the oil yield.

\section{ASSOCIATED CONTENT}

\section{S Supporting Information}

The Supporting Information is available free of charge on the ACS Publications website at DOI: 10.1021/acs.energyfuels.8b03519.

Figure S1, EDX mapping of the spent non-presulfided NiMo-II catalyst from reaction of H-LS at $310{ }^{\circ} \mathrm{C}$ and accumulation of $\mathrm{Ni}$ and formation of $\mathrm{Ni}_{3} \mathrm{~S}_{2}$; Figure S2, HSQC NMR of the oil fraction from catalytic conversion of $\mathrm{H}-\mathrm{LS}$ in nitrogen atmosphere at $310^{\circ} \mathrm{C}$; Figure S3, physical appearance of the solid fractions from noncatalytic and catalytic conversion of H-LS at $310{ }^{\circ} \mathrm{C}$; Table S1, selectivity of the compounds identified by GC-MS-FID analysis of the oil fractions from conversion of $\mathrm{H}$-LS over non-presulfided and presulfided NiMo-I at $310^{\circ} \mathrm{C}$; Figure S4, SEC results of the oil fractions obtained from catalytic conversion of $\mathrm{H}$ LS at 260 and $310^{\circ} \mathrm{C}$; Figure S5, HSQC NMR of the oil fraction from catalytic conversion of $\mathrm{H}-\mathrm{LS}$ at $310^{\circ} \mathrm{C}$ and $1 \mathrm{~h}$ reaction time; Figure S6, HSQC NMR of the oil fraction from catalytic conversion of $\mathrm{H}-\mathrm{LS}$ at $310^{\circ} \mathrm{C}$ and $2 \mathrm{~h}$ reaction time; Figure S7, HSQC NMR of the oil fraction from catalytic conversion of H-LS at $310^{\circ} \mathrm{C}$ and $4 \mathrm{~h}$ reaction time; Figure S8, SEC of the oil fractions from catalytic conversion of $\mathrm{H}-\mathrm{LS}$ at $310^{\circ} \mathrm{C}$ for different reaction times; Figure S9, SEC of the oil fractions from catalytic conversion of $\mathrm{H}-\mathrm{LS}$ at $310{ }^{\circ} \mathrm{C}$ with varied catalyst loadings (PDF)

\section{AUTHOR INFORMATION}

Corresponding Author

*(A.D.J.) E-mail: aj@kt.dtu.dk. Telephone: +45 45252841. ORCID $\odot$

Daniel Bo Larsen: 0000-0002-8647-536X

Jens Øllgaard Duus: 0000-0003-3625-1250
Anker Degn Jensen: 0000-0002-7341-4859

\section{Author Contributions}

The manuscript was written through contributions of all authors. All authors have given approval to the final version of the manuscript. Authors specified with the same symbol contributed equally.

\section{Notes}

The authors declare no competing financial interest.

\section{ACKNOWLEDGMENTS}

This research was funded by Bio-Value SPIR, which is cofounded by The Innovation Fund Denmark, Grant No. 0603-00522B. We are grateful to Haldor Topsøe A/S and Borregaard A/S for supplying the catalyst and lignosulfonate, respectively. The NMR Center at Chemistry Department, DTU, is thanked for access to the $400 \mathrm{MHz}$ spectrometer. Provision of the catalyst support material by Saint Gobain is acknowledged. The authors C.S. and C.D.D. acknowledge funding from the Danish Research Council for Technology and Production (FTP), Grant No. 4005-00293.

\section{ABBREVIATIONS}

CoMo, cobalt-promoted Mo; DAF, dry and ash free; DMDS, dimethyl disulfide; DMSO, dimethyl sulfoxide; FID, flame ionization detector; GC, gas chromatography; GGGE, guaiacylglycerol $\beta$-guaiacyl ether; $\mathrm{HDN}$, hydrodenitrogenation; HDO, hydrodeoxygenation; HDS, hydrodesulfurization; HHV, high heating value; H-LS, sulfonic acid lignosulfonate; HSQC NMR, heteronuclear single quantum coherence nuclear magnetic resonance; ICP-OES, ion-coupled plasma-optical emission spectroscopy; MS, mass spectrometry; NiMo, $\mathrm{Ni}$ promoted Mo; RT, room temperature; SEC, size exclusion chromatography; TCD, thermal conductivity detector;

\section{REFERENCES}

(1) Brunner, G. Processing of biomass with hydrothermal and supercritical water. Supercritical Fluid Science and Technology 2014, 5, 395-509.

(2) Isikgor, F. H.; Becer, C. R. Lignocellulosic biomass: A sustainable platform for production of bio-based chemicals and polymers. Polym. Chem. 2015, 6, 4497-4559.

(3) Dutta, S.; Wu, KC-W; Saha, B. Emerging strategies for breaking the 3D amorphous network of lignin. Catal. Sci. Technol. 2014, 4, 3785-99.

(4) Aro, T.; Fatehi, P. Production and application of lignosulfonates and sulfonated Lignin. ChemSusChem 2017, 10, 1861-77.

(5) Rinaldi, R.; Jastrzebski, R.; Clough, M. T.; Ralph, J.; Kennema, M.; Bruijnincx, P. C. A.; et al. Paving the Way for Lignin Valorisation: Recent Advances in Bioengineering, Biorefining and Catalysis. Angew. Chem., Int. Ed. 2016, 55, 8164-215.

(6) Nielsen, J. B.; Jensen, A.; Schandel, C. B.; Felby, C.; Jensen, A. D. Solvent consumption in non-catalytic alcohol solvolysis of biorefinery lignin. Sustain Energy Fuels 2017, 1, 2006-15.

(7) Huang, X.; Korányi, T. I.; Boot, M. D.; Hensen, E. J. M. Ethanol as capping agent and formaldehyde scavenger for efficient depolymerization of lignin to aromatics. Green Chem. 2015, 17, 4941-50.

(8) Chen, P.; Zhang, Q.; Shu, R.; Xu, Y.; Ma, L.; Wang, T. Catalytic depolymerization of the hydrolyzed lignin over mesoporous catalysts. Bioresour. Technol. 2017, 226, 125-31.

(9) Wang, X.; Rinaldi, R. Solvent effects on the hydrogenolysis of diphenyl ether with raney nickel and their implications for the conversion of lignin. ChemSusChem 2012, 5, 1455-66.

(10) Kim, J.-Y.; Park, J.; Hwang, H.; Kim, J. K.; Song, I. K.; Choi, J. W. Catalytic depolymerization of lignin macromolecule to alkylated 
phenols over various metal catalysts in supercritical tert-butanol. J. Anal. Appl. Pyrolysis 2015, 113, 99-106.

(11) Kumar, C. R.; Anand, N.; Kloekhorst, A.; Cannilla, C.; Bonura, G.; Frusteri, F.; et al. Solvent free depolymerization of Kraft lignin to alkyl-phenolics using supported NiMo and CoMo catalysts. Green Chem. 2015, 17, 4921-4930.

(12) Klass, D. L. Biomass for renewable energy, fuels, and chemicals. Encycl Energy 2004, 1, 193-212.

(13) Maxted, E. B. The poisoning of metallic catalysts. Adv. Catal. 1951, 3, 129-78.

(14) Li, M-F.; Sun, S-N.; Xu, F.; Sun, R-C. Organosolv fractionation of lignocelluloses for fuels, chemicals and materials: a biorefinery processing perspective. Biomass Convers. - interface Biotechnol. Chem. Mater. Sci. 2012, 341-379.

(15) Zakzeski, J.; Bruijnincx, P. C. A.; Jongerius, A. L.; Weckhuysen, B. M. The catalytic valorization of lignin for the production of renewable chemicals. Chem. Rev. 2010, 110, 3552-99.

(16) Mahmood, N.; Yuan, Z.; Schmidt, J.; Xu, C. Depolymerization of lignins and their applications for the preparation of polyols and rigid polyurethane foams: A review. Renewable Sustainable Energy Rev. 2016, 60, 317-329.

(17) Busca, G. Catalysts for hydrogenations, dehydrogenations and metathesis: Sulfides and oxides. Heterog. Catal. Mater. 2014, 345374.

(18) Lauritsen, J. V.; Kibsgaard, J.; Olesen, G. H.; Moses, P. G.; Hinnemann, B.; Helveg, S.; et al. Location and coordination of promoter atoms in Co- and Ni-promoted MoS2-based hydrotreating catalysts. J. Catal. 2007, 249, 220-33.

(19) Zhu, Y.; Ramasse, Q. M.; Brorson, M.; Moses, P. G.; Hansen, L. P.; Topsøe, H.; et al. Location of $\mathrm{Co}$ and Ni promoter atoms in multilayer MoS2 nanocrystals for hydrotreating catalysis. Catal. Today 2016, 261, 75-81.

(20) Boon, A. Q. M.; Powell, J. B. Method of extending biomass conversion catalyst life. WO2017/106228A1, 2017.

(21) Narani, A.; Chowdari, R. K.; Cannilla, C.; Bonura, G.; Frusteri, F.; Heeres, H. J.; et al. Efficient catalytic hydrotreatment of Kraft lignin to alkylphenolics using supported NiW and NiMo catalysts in supercritical methanol. Green Chem. 2015, 17, 5046-57.

(22) Cattelan, L.; Yuen, A. K. L.; Lui, M. Y.; Masters, A. F.; Selva, M.; Perosa, A.; et al. Renewable aromatics from kraft lignin with molybdenum-based catalysts. ChemCatChem 2017, 9, 2717-26.

(23) Joffres, B.; Lorentz, C.; Vidalie, M.; Laurenti, D.; Quoineaud, A.-A.; Charon, N.; et al. Catalytic hydroconversion of a wheat straw soda lignin : Characterization of the products and the lignin residue. Appl. Catal., B 2014, 145, 167-76.

(24) Joffres, B.; Nguyen, M. T.; Laurenti, D.; Lorentz, C.; Souchon, V.; Charon, N.; et al. Lignin hydroconversion on $\mathrm{MoS}_{2}$-based supported catalyst: Comprehensive analysis of products and reaction scheme. Appl. Catal., B 2016, 184, 153-62.

(25) Shu, R.; Xu, Y.; Ma, L.; Zhang, Q.; Wang, T.; Chen, P.; et al. Hydrogenolysis process for lignosulfonate depolymerization using synergistic catalysts of noble metal and metal chloride. RSC Adv. 2016, 6, 88788-88796.

(26) Song, Q.; Wang, F.; Xu, J. Hydrogenolysis of lignosulfonate into phenols over heterogeneous nickel catalysts. Chem. Commun. 2012, 48, 7019-21.

(27) Horáček, J.; Mikkola, J.-P.; Samikannu, A.; Št'Ávová, G.; Larsson, W.; Hora, L.; et al. Studies on sodium lignosulfonate depolymerization over $\mathrm{Al} 2 \mathrm{O} 3$ supported catalysts loaded with metals and metal oxides in a continuous flow reactor. Top. Catal. 2013, 56, 794-9.

(28) Brand, S.; Hardi, F.; Kim, J.; Suh, D. J. Effect of heating rate on biomass liquefaction: Differences between subcritical water and supercritical ethanol. Energy 2014, 68, 420-7.

(29) Mortensen, P. M.; Gardini, D.; Damsgaard, C. D.; Grunwaldt, J.; Jensen, P. A.; Wagner, J. B.; et al. Deactivation of Ni-MoS2 by biooil impurities during hydrodeoxygenation of phenol and octanol. Appl. Catal., A 2016, 523, 159-70.
(30) Fredheim, G. E.; Braaten, S. M.; Christensen, B. E. Molecular weight determination of lignosulfonates by size-exclusion chromatography and multi-angle laser light scattering. J. Chromatogr A 2002, 942, 191-9.

(31) Dabros, T. M. H.; Gaur, A.; Pintos, D. G.; Sprenger, P.; Høj, M.; Hansen, T. W.; et al. Influence of $\mathrm{H}_{2} \mathrm{O}$ and $\mathrm{H}_{2} \mathrm{~S}$ on the composition, activity, and stability of sulfided $\mathrm{Mo}, \mathrm{CoMo}$, and NiMo supported on $\mathrm{MgAl}_{2} \mathrm{O}_{4}$ for hydrodeoxygenation of ethylene glycol. Appl. Catal., A 2018, 551, 106-21.

(32) Medici, L.; Prins, R. The influence of chelating ligands on the sulfidation of $\mathrm{Ni}$ and $\mathrm{Mo}$ in $\mathrm{NiMo} / \mathrm{SiO} 2$ hydrotreating catalysts. $J$. Catal. 1996, 163, 38-49.

(33) Ma, R.; Hao, W.; Ma, X.; Tian, Y.; Li, Y. Catalytic ethanolysis of kraft lignin into high-value small-molecular chemicals over a nanostructured a-molybdenum carbide catalyst. Angew. Chem., Int. Ed. 2014, 53, 7310-5.

(34) Oregui-Bengoechea, M.; Gandarias, I.; Miletic, N.; Simonsen, S. F.; Kronstad, A.; Arias, P. L.; et al. Thermocatalytic conversion of lignin in an ethanol/formic acid medium with NiMo catalysts: Role of the metal and acid sites. Appl. Catal., B 2017, 217, 353-64.

(35) Hamabe, Y.; Jung, S.; Suzuki, H.; et al. Quasi in situ Ni K -edge EXAFS investigation of the spent NiMo catalyst from ultra-deep hydro- desulfurization of gas oil in a commercial plant research papers. J. Synchrotron Radiat. 2010, 17, 530-539.

(36) Wadenback, J.; Clapham, D.; Gellerstedt, G.; von Arnold, S. Variation in content and composition of lignin in young wood of Norway spruce. Holzforschung 2004, 58, 107-15.

(37) Hicks, J. C. Advances in C-O bond transformations in ligninderived compounds for biofuels production. J. Phys. Chem. Lett. 2011, $2,2280-7$.

(38) Wen, J.-L.; Sun, S.-L.; Yuan, T.-Q.; Sun, R.-C. Structural elucidation of whole lignin from Eucalyptus based on preswelling and enzymatic hydrolysis. Green Chem. 2015, 17, 1589-96.

(39) Yin, H.-S.; Liu, H.-M.; Liu, Y.-L. Structural characterization of lignin in fruits and stalks of Chinese quince. Molecules 2017, 22, 890903.

(40) Zhang, T.; Zhou, Y.; Liu, D.; Petrus, L. Qualitative analysis of products formed during the acid catalyzed liquefaction of bagasse in ethylene glycol. Bioresour. Technol. 2007, 98, 1454-9.

(41) Nielsen, J. B.; Jensen, A.; Madsen, L. R.; Larsen, F. H.; Felby, C.; Jensen, A. D. Noncatalytic direct liquefaction of biorefinery lignin by ethanol. Energy Fuels 2017, 31, 7223-33.

(42) Demirel, Y. Energy and Energy Types. Energy. Green Energy Technol. First 2012, 27-70.

(43) Van den Bosch, S.; Renders, T.; Kennis, S.; Koelewijn, S.-F.; Van den Bossche, G.; Vangeel, T.; et al. Integrating lignin valorization and bio-ethanol production: on the role of $\mathrm{Ni}-\mathrm{Al} 2 \mathrm{O} 3$ catalyst pellets during lignin-first fractionation. Green Chem. 2017, 19, 3313-26.

(44) Yuan, Z.; Tymchyshyn, M.; Xu, C. Reductive depolymerization of kraft and organosolv lignin in supercritical acetone for chemicals and materials. ChemCatChem 2016, 8, 1968-1976. 